ARTICLE

Received 21 Apr 2014 | Accepted 22 Jan 2015 | Published 27 Feb 2015

DOI: $10.1038 /$ ncomms 7354

\title{
The cholesterol transporter ABCG1 links cholesterol homeostasis and tumour immunity
}

Duygu Sag ${ }^{1, \star}$, Caglar Cekic ${ }^{2, \star}$, Runpei Wu${ }^{1}$, Joel Linden $^{3} \&$ Catherine C. Hedrick ${ }^{1}$

ATP-binding cassette transporter G1 (ABCG1) promotes cholesterol efflux from cells and regulates intracellular cholesterol homeostasis. Here we demonstrate a role of $A B C G 1$ as a mediator of tumour immunity. Abcg $1^{-/}$mice have dramatically suppressed subcutaneous MB49-bladder carcinoma and B16-melanoma growth and prolonged survival. We show that reduced tumour growth in $A b c g 1^{-/}$mice is myeloid cell intrinsic and is associated with a phenotypic shift of the macrophages from a tumour-promoting M2 to a tumour-fighting M1 within the tumour. $\mathrm{Abcg} 1^{-/-}$macrophages exhibit an intrinsic bias towards $\mathrm{M} 1$ polarization with increased NF- $\mathrm{B}$ B activation and direct cytotoxicity for tumour cells in vitro. Overall, our study demonstrates that the absence of $A B C G 1$ inhibits tumour growth through modulation of macrophage function within the tumour, and illustrates a link between cholesterol homeostasis and cancer.

\footnotetext{
${ }^{1}$ Division of Inflammation Biology, La Jolla Institute for Allergy and Immunology, La Jolla, California 92037, USA. ${ }^{2}$ Department of Molecular Biology and Genetics, Bilkent University, Ankara 06800, Turkey. ${ }^{3}$ Division of Developmental Immunology, La Jolla Institute for Allergy and Immunology, La Jolla, California 92037, USA. * These authors contributed equally to this work. Correspondence and requests for materials should be addressed to D.S. (email: dsag@liai.org) or to C.C.H. (email: hedrick@liai.org).
} 
$\mathrm{n}$ addition to the cancer cells and their surrounding stroma, the tumour microenvironment contains innate and adaptive immune cells that can recognize and destroy tumours ${ }^{1}$. However, the tumour not only manages to evade the immune system through various mechanisms, but also it contrives to benefit from infiltrating immune cells by modifying their functions to create a microenvironment favourable to tumour progression $^{2}$. Macrophages are major players of tumour immunity. Monocyte-derived macrophages can polarize into either M1 (classically activated) or M2 (alternatively activated) macrophage subtypes in the presence of specific polarization factors, including cytokines, growth factors and bioactive lipids, when recruited into peripheral tissues ${ }^{3,4}$. In general, M1 macrophages are potent tumour-fighting cells, whereas M2 macrophages display protumoral functions. The tumour recruits blood monocytes and promotes their differentiation mostly into M2-like macrophages ${ }^{5}$. M2-like tumour-associated macrophages (TAMs) play a key role in tumour growth and progression by producing molecules to promote angiogenesis, as well as survival and metastasis of tumour cells ${ }^{6-9}$. Moreover, TAMs affect adaptive immune responses by recruiting $\mathrm{T}$ regulatory cells (Tregs), which in turn suppress antitumour effector cells such as $\mathrm{NK}$ cells and $\mathrm{CD} 4^{+} / \mathrm{CD} 8{ }^{+} \mathrm{T}$ cells ${ }^{10}$. Several studies have reported a positive correlation between high TAM density and poor prognosis in human tumours, including bladder, breast and prostate $^{7,11}$. Furthermore, it has been shown in different murine tumour models that either depletion of macrophages ${ }^{12-16}$ or switching the phenotype of macrophages into tumour-fighting M1 macrophages ${ }^{17-19}$ results in a significant reduction in tumour growth.

ATP-binding cassette transporter G1 (ABCG1) is a member of the $\mathrm{ABC}$ transporter family that regulates cellular cholesterol homeostasis ${ }^{20}$. Cholesterol homeostasis is crucial for the survival and function of cells ${ }^{21}$. ABCG1 effluxes excess cholesterol from cells to high-density lipoprotein (HDL) particles for reverse cholesterol transport, which is the only path for elimination of cholesterol from the body ${ }^{22,23}$. ABCG1 is also important for the intracellular transport of cholesterol ${ }^{24,25}$. It is ubiquitously expressed in many cell types including myeloid cells, lymphocytes and endothelial cells ${ }^{20}$.

ABCG1 is known to regulate several aspects of macrophage biology. Abcg1 $1^{-1-}$ mice fed a Western-like diet display excessive lipid accumulation in macrophages ${ }^{22}$. Atherosclerosis studies demonstrated that ABCG1-deficient macrophages were more susceptible to apoptosis compared with wild-type (WT) macrophages under Western-like diet conditions in vivo ${ }^{26,27}$. Furthermore, $A b c g 1^{-1-}$ macrophages have been shown to display enhanced proinflammatory cytokine production at basal level ${ }^{28,29}$, in response to lipopolysaccharide (LPS) ${ }^{30}$ and when loaded with cholesterol ${ }^{31}$. ABCG1 also plays a role in T-cell biology. We and others have reported that alterations in intracellular cholesterol homeostasis in the absence of ABCG1 increase proliferation of $\mathrm{CD}^{+} \mathrm{T}$ cells ${ }^{32,33}$ and impairs development of invariant natural killer $\mathrm{T}$ cells in thymus ${ }^{34}$.
Overall, changes in cholesterol homeostasis by the absence of ABCG1 modulate immune cell function; however, the role of ABCG1 in antitumour immune responses is unknown.

In this study, we demonstrate that the in vivo deficiency of ABCG1 reduces tumour growth and increases the survival of mice. Reduced tumour growth in the absence of ABCG1 is mediated by myeloid cell intrinsic mechanisms and is associated with a shift of macrophages to a tumour-fighting M1 phenotype within the tumour, which results in the direct killing of tumour cells.

\section{Results}

ABCG1 deficiency prevents tumour growth in mice. To determine if ABCG1 has an impact on tumour growth, MB49-bladder carcinoma or B16-F1 melanoma cells were first injected subcutaneously into 7-10-week-old $A b c g 1^{-1-}$ or control C57BL/6 (WT) mice fed a regular rodent chow diet (containing $0 \%$ cholesterol and 5\% calories from fat; Fig. 1a). Both groups of mice had comparable MB49 and B16-F1 tumour sizes when fed a chow diet (Fig. 1b,c). Because ABCG1 regulates cholesterol homeostasis in the cell, to make the impact of ABCG1 deficiency more prominent, 7-10-week-old $A b c g 1^{-1-}$ and WT mice were next fed a Western-like diet (containing $0.2 \%$ cholesterol and $42 \%$ calories from fat) beginning a week before MB49 or B16-F1 tumour inoculation. The Western-like diet used in our studies is very similar in cholesterol and fat content to the typical Western-like diet chosen by many people in developed countries, and now increasingly in developing countries. Abcg1-/- mice fed a Western-like diet displayed dramatically reduced MB49 (fourfold at day 20) and B16-F1 (approximately threefold at day 20) tumour growth compared with control mice (Fig. 1d,e). By 6-8 months of age, Abcg1-I- mice develop age-dependent phenotypes, such as pulmonary lipidosis and massive lipid deposition in macrophages ${ }^{35}$ and these phenotypes are known to be accelerated by a Western-like $\operatorname{diet}^{22}$. Therefore, we also assessed the tumour growth in older (6-7 months old) Abcg1 $1^{-1-}$ and WT mice fed a chow diet. Interestingly, we found that aged $A b c g 1^{-1}-$ mice when fed a chow diet had dramatically reduced MB49 tumour growth compared with aged-matched WT controls (Fig. 1f).

To investigate how Western-like diet affects the cholesterol profiles of tumour-bearing $A b c g 1^{-1-}$ and WT mice, we performed fast protein liquid chromatography analysis of plasma lipoprotein cholesterol profiles of MB49 tumour-bearing (day 12) 7-10-week-old Abcg1-I- and WT mice fed either chow or Western-like diets. In line with the published literature on Abcg1 ${ }^{-1-}$ mice ${ }^{24,36}$, plasma lipoprotein cholesterol profiles of tumour-bearing $A b c g 1^{-1-}$ and WT mice were similar. In addition, Western-like diet feeding increased plasma lipoprotein cholesterol levels in both groups of mice (Fig. 1g). To further investigate the impact of ABCG1 deficiency on tumour progression, we crossed $A b c g 1^{-/-}$mice with apoE-deficient $\left(A p o E^{-I^{-}}\right)^{37,38}$ and LDL-receptor-deficient mice $\left(\mathrm{Ldlr}^{-/-}\right)^{39,40}$

Figure 1 | ABCG1 deficiency reduces MB49 and B16 tumour growth. (a) Schematic diagram of the experimental design is shown. Graphs show (b) MB49 and (c) B16-F1 tumour growth in chow diet-fed and (d) MB49 and (e) B16-F1 tumour growth in Western-like diet-fed 7-10-week-old Abcg1- $/-$ ( $n=8$ ) and C57BL/6 (WT) mice $(n=8)$ and (f) MB49 tumour growth in chow diet-fed 6-7-month-old Abcg ${ }^{-/-}$( $n=6$ ) and WT ( $n=7$ ) mice. (g) Blood plasma from five tumour-bearing mice for each group was pooled and the lipoprotein profile was analysed by fast protein liquid chromatography. Graph shows VLDL, IDL/LDL and HDL levels in all groups. (h-j) Graphs show MB49 tumour growth in (h) chow diet-fed and (i) Western-like diet-fed Abcg1-/ -

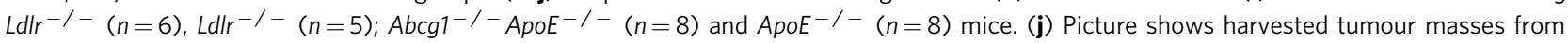
Western-like diet-fed $A b c g 1^{-/-} A p o E^{-/-}$and $A p o E^{-/-}$mice at day 21. Data are representative of two to four independent experiments with similar results. (mean \pm s.e.m., ${ }^{\star \star \star} P<0.001$, two-way analysis of variance test). (k) Graph shows Kaplan-Meier survival curve of Western-like diet-fed tumour (MB49)-bearing Abcg1-I- $(n=5)$ and WT mice $(n=5)$. Data are representative of two independent experiments with similar results (mean \pm s.e.m., ${ }^{\star} P<0.05$, log-rank test). IDL, intermediate-density lipoprotein; LDL, low-density lipoprotein; VLDL, very low-density lipoprotein. 
The ApoE ${ }^{-I-}$ and $L d l r^{-I-}$ models are two hypercholesterolemic mouse models that are widely used to study atherosclerosis. Both genotypes have high plasma cholesterol levels when fed a chow diet and show profoundly increased plasma cholesterol levels when fed a Western-like $\operatorname{diet}^{37-41}$. We first compared the plasma lipoprotein cholesterol profiles of MB49 tumour-bearing (day 12) 7-10-week-old $A b c g 1^{-I-} A p o E^{-I-}$ mice with $A p o E^{-/-}$mice and $A b c g 1^{-1-} L d l r^{-I-}$ mice with $L d l r^{-I-}$ mice, all fed a chow

a
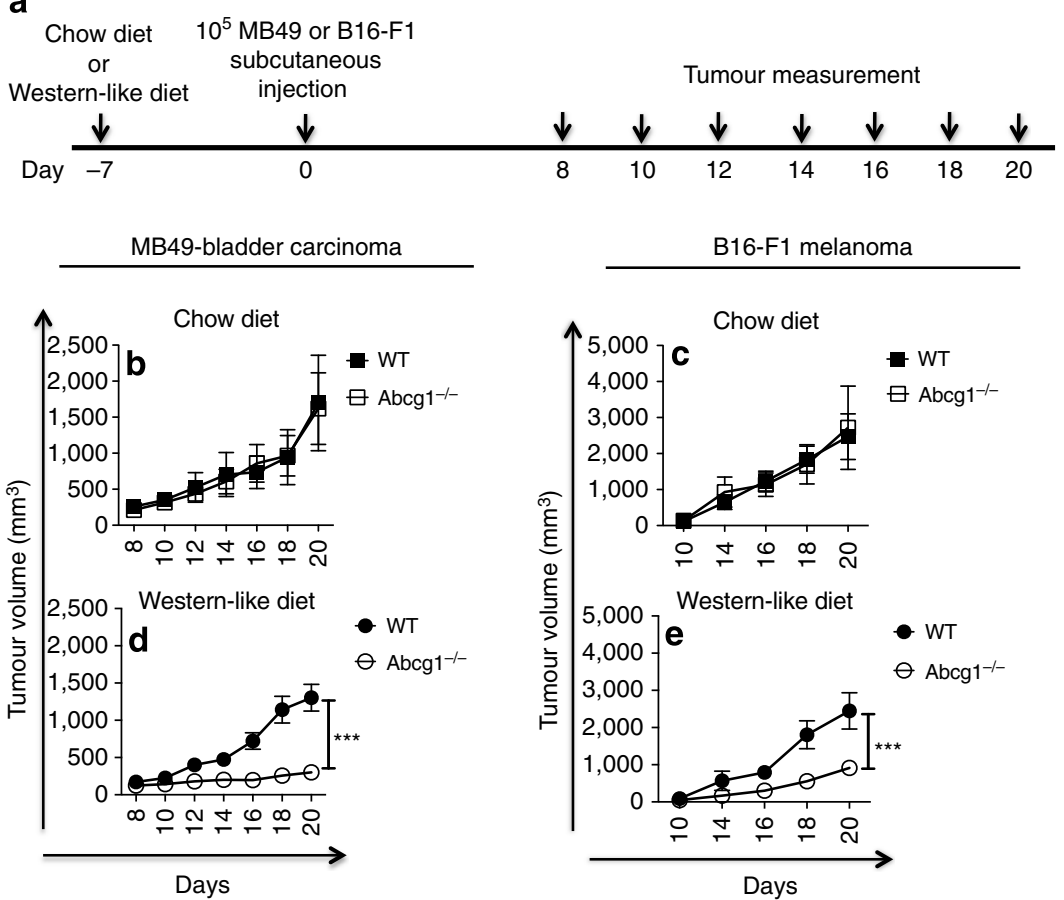

MB49-bladder carcinoma

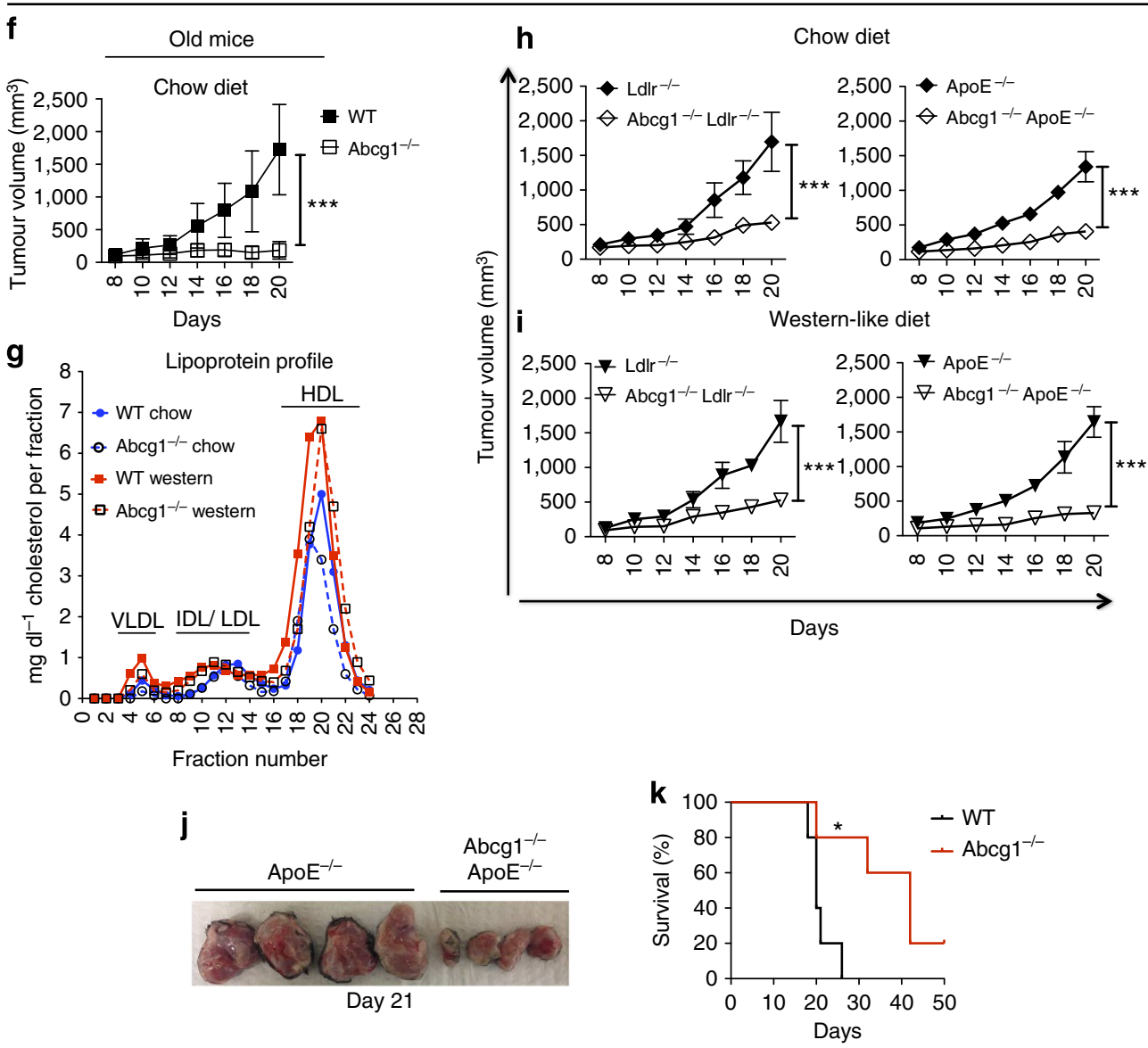


a

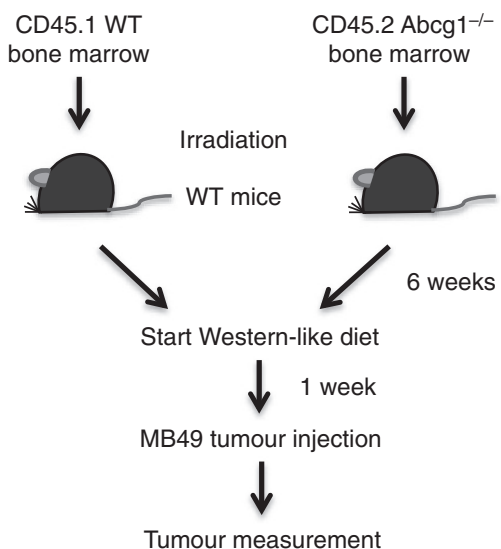

b

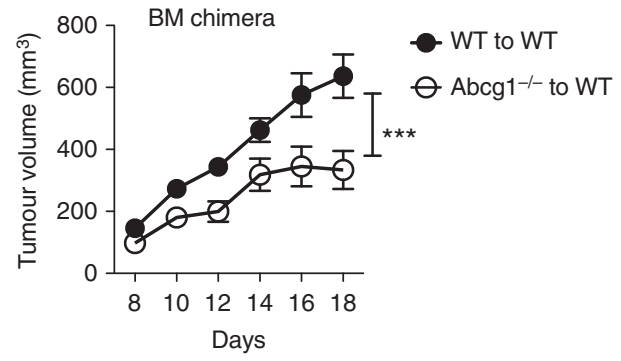

C
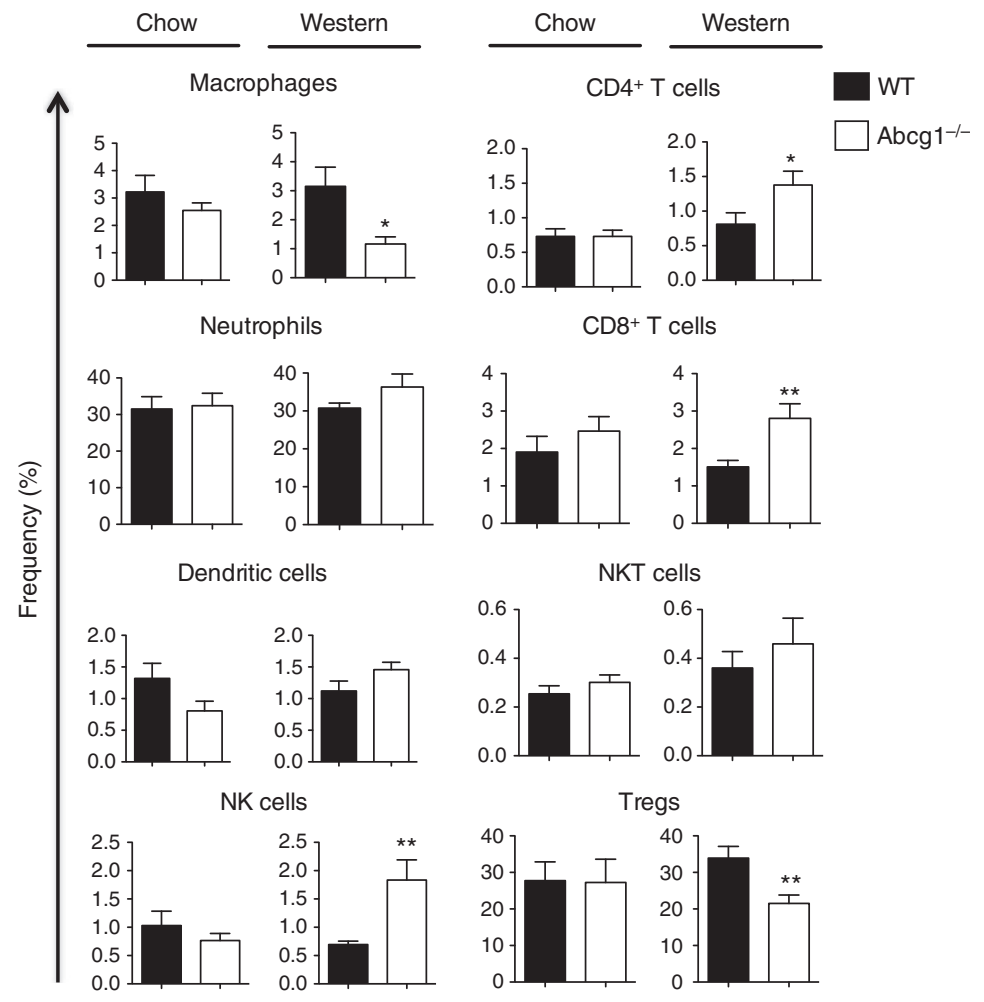

Figure 2 I Impact of ABCG1 deficiency on tumour growth is immune cell mediated. (a,b) Bone marrow chimeras were generated by reconstituting

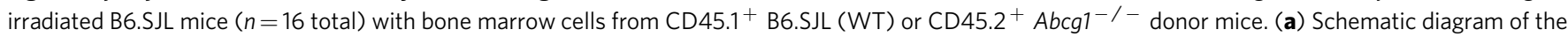
experimental design is shown. (b) Graph shows MB49 tumour growth in the chimeric mice. Data are representative of two independent experiments with similar results ( ${ }^{\star \star \star} P<0.001$, two-way analysis of variance test). (c) Tumour cells from $A b c g 1^{-/-}$and $C 57 \mathrm{BL} / 6(\mathrm{WT})$ mice ( $n=5-7$ per group) were analysed by flow cytometry 20 days after injection of MB49 cells. Bar graphs show the frequencies of macrophages, neutrophils, DCs, NK cells, CD4 + T cells, CD8 ${ }^{+}$T cells, NKT cells (\% of live cells) and Tregs (\% of CD4 ${ }^{+}$T cells) in the tumour. (See methods and Supplementary Fig. 2 for gating strategies). Data are pooled from two independent experiments with similar results (mean \pm s.e.m., ${ }^{\star} P<0.05,{ }^{\star \star} P<0.01$, two-tailed Student's $t$-test).

diet. We found that the loss of ABCG1 had no impact on plasma lipoprotein profiles in tumour-bearing hypercholesterolemic mice (Supplementary Fig. 1). We next measured subcutaneous tumour growth in $A b c g 1^{-}$mice crossed with these hypercholesterolemic mouse models. Interestingly, both 7-10-week-old Abcg1-I- $\mathrm{Ldlr}^{-1-}$ and $A b c g 1^{-1-} A p o E^{-1-}$ chow-fed mice showed dramatically reduced MB49 tumour growth compared with chow-fed control $L d l r^{-I-}$ and $A p o E^{-1-}$ mice, respectively (Fig. 1h). Both genotypes also displayed a profound reduction in tumour growth when fed a Western-like diet (Fig. 1i,j). Collectively, these data show that Western-like diet feeding or crossing with hypercholesterolemic mice is necessary to observe the changes in tumour growth in young $A b c g 1^{-1-}$ mice, while this tumour phenotype is evident in aged $A b c g 1^{-1-}$ mice fed a chow diet.

To investigate the impact of ABCG1 deficiency on spontaneous tumour metastasis, we utilized luciferase-expressing B16-F10 cells (B16-F10-luc2). B16-F10-luc2 cells were injected subcutaneously into Western-like diet-fed $A b c g 1^{-1}$ or WT mice. B16-F10-luc2 tumours grew aggressively and by day 28 , the difference in tumour growth between $A b c g 1^{-1-}$ and WT mice was significant, but not very prominent (Supplementary Fig. 2). This aspect of B16-F10-luc2 tumour growth allowed us to choose mice for study that had similar-sized tumours. Lungs from mice with similar, but average, tumour sizes in both groups were analysed for spontaneous metastases of B16-F10 melanoma by bioluminescence imaging ex vivo (Supplementary Fig. 2). Subcutaneous B16 transplants have been shown to spontaneously metastasize to lung ${ }^{42,43}$. Abcg1 $1^{-1-}$ mice had significantly diminished tumour metastasis compared with WT mice (Supplementary Fig. 2). Subsequently, we examined the impact of ABCG1 deficiency on survival of tumour-bearing mice. MB49 tumour-bearing $A b c g 1^{-1-}$ mice showed prolonged survival compared with WT mice when fed a Western-like diet (Fig. 1k). Collectively, these data demonstrate that in vivo deficiency of ABCG1 impairs tumour growth and increases animal survival.

Reduction in tumours in $A b c g 1^{-/-}$mice is immune mediated. To determine if the impact of ABCG1 deficiency on tumour growth is mediated by immune cells, we used a bone marrow chimera approach. We measured MB49 tumour growth in Western-like diet-fed irradiated CD45.1 ${ }^{+}$B6.SJL (WT) mice, which were reconstituted with CD $45.2^{+} \mathrm{Abcg} 1^{-/}$or CD $45.1^{+}$ B6.SJL bone marrow (Fig. 2a). WT mice reconstituted with Abcg1 $1^{-1}$ bone marrow had a significant reduction in tumour growth over time compared with WT mice reconstituted with WT bone marrow (Fig. 2b), demonstrating that the impact of ABCG1 deficiency on tumour growth is immune cell mediated.

The tumour microenvironment contains innate and adaptive immune cells, which display pro or antitumour functions. While NK cells, M1 macrophages, CD4 ${ }^{+}$Th1 cells and $\mathrm{CD} 8{ }^{+} \mathrm{T}$ have been shown to act as tumour-fighting cells, M2 macrophages and Tregs in tumour are known to support tumour progression. 
a

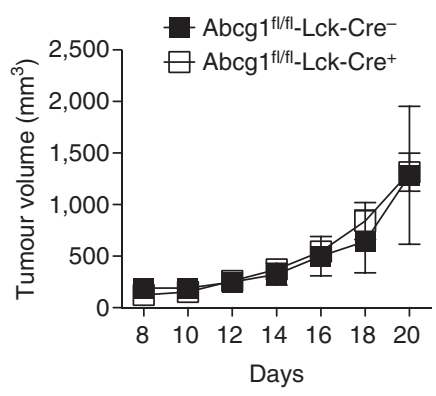

b

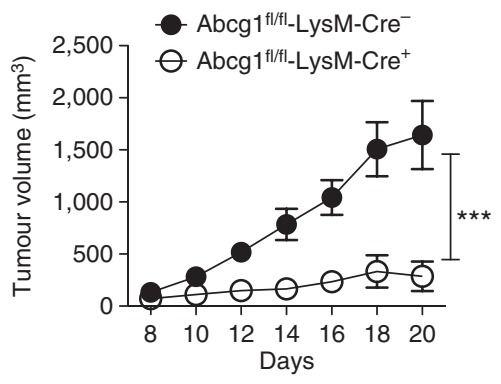

c

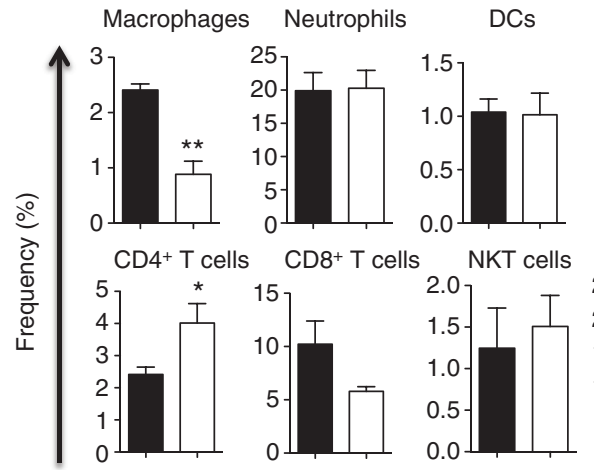

Abcg $1^{\text {fl/fl-LysM-Cre }}{ }^{-}$

Abcg $1^{\mathrm{fl} / \mathrm{fl} \text {-LysM-Cre }}{ }^{+}$

NK cells

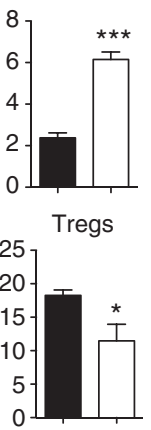

Abcg $1^{\mathrm{fl} / \mathrm{fl} \text {-LysM-Cre }}{ }^{-}$

Abcg $1^{\mathrm{fl} / \mathrm{fl} \text {-LysM-Cre }}{ }^{+}$

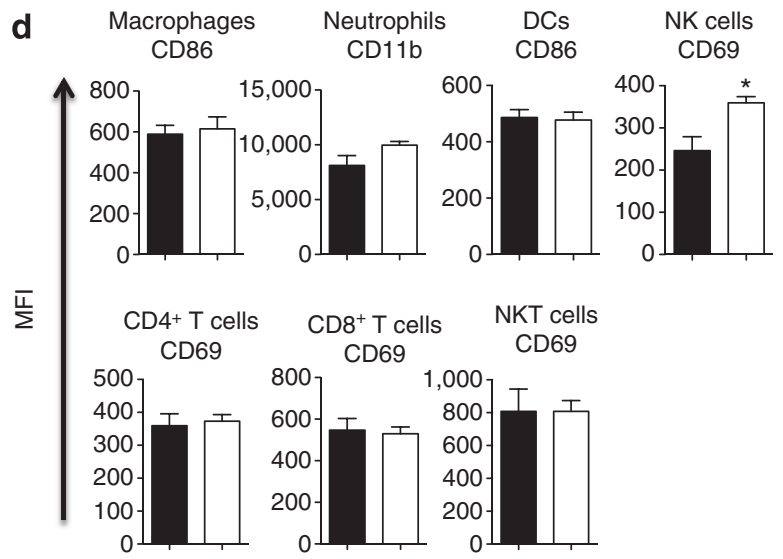

Figure 3 | Reduced tumour growth in $\mathbf{A b c g} \mathbf{1}^{-1-}$ mice is myeloid cell intrinsic. Graphs show MB49 tumour growth in Western-like diet-fed

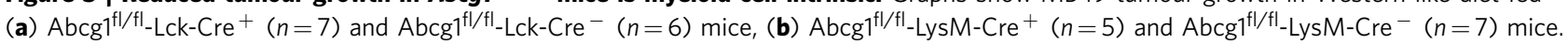
Data are representative of two independent experiments with similar results ( ${ }^{\star \star} P<0.001$, two-way analysis of variance test). Tumour cells from Western-like diet-fed Abcgf ${ }^{\mathrm{fl} / \mathrm{fl}}$-LysM-Cre ${ }^{+}(n=5)$ and Abcg $\mathrm{f}^{\mathrm{fl} / \mathrm{fl}}$-LysM-Cre ${ }^{-}$mice $(n=5)$ were analysed by flow cytometry 20 days after injection of MB49 cells. (c) Bar graphs show the frequencies of macrophages, neutrophils, DCs, NK cells, CD4 ${ }^{+}$T cells, CD8 ${ }^{+}$T cells, NKT cells (\% of live cells) and Tregs (\% of CD4 ${ }^{+}$T cells) in tumour (See methods and Supplementary Fig. 2 for gating strategies). (d) Bar graphs show the MFI of indicated activation markers on immune cells in the tumour. Data are representative of two independent experiments with similar results (mean \pm s.e.m., ${ }^{\star} P<0.05$, ${ }^{\star \star} P<0.01,{ }^{\star \star \star} P<0.001$, two-tailed Student's $t$-test).

Dendritic cells (DCs), neutrophils and NKT cells have been shown to exert both tumour-suppressive and -promoting effects $^{1,44}$. Next we wanted to define the primary immune cell populations in the tumour microenvironment that are affected by the absence of ABCG1 under Western-like diet conditions. MB49 tumour cells were injected subcutaneously into either Westernlike diet-fed or chow diet-fed $A b c g 1^{-1}$ and WT mice and tumour-infiltrating immune cells were analysed by flow cytometry (For gating strategy, see Supplementary Fig. 3). We found that the frequencies of macrophages and Tregs significantly decreased, whereas the frequencies of NK cells, CD4 ${ }^{+} \mathrm{T}$ cells and CD8 ${ }^{+} \mathrm{T}$ cells significantly increased in the tumours of Westernlike diet-fed $A b c g 1^{-1-}$ mice compared with WT mice (Fig. 2c). No significant differences were observed in the frequencies of tumour-infiltrating neutrophils, DCs or NKT cells in chow dietfed or Western-like diet-fed $A b c g 1^{-1-}$ or WT mice (Fig. 2c). These results demonstrate that ABCG1 deficiency changes the balance between tumour-promoting and tumour-fighting immune cells within the tumour microenvironment.

Tumour reduction in $A b c g 1^{-I-}$ mice is myeloid cell mediated. To determine which cell type(s) were intrinsically affected by the absence of ABCG1 to impact tumour growth, we deleted ABCG1 selectively in either myeloid cells or $\mathrm{T}$ cells using Cre/loxP technology. We generated conditional knockout mice $\left(A b c g 1^{\mathrm{fl} / \mathrm{fl}}\right)$ in which loxP sites flank the Walker domain of exon 3 of $A b c g 1$ and crossed them with either LysM-Cre or Lck-Cre mice for selective deletion of ABCG1 in myeloid cells and $\mathrm{T}$ cells, respectively ${ }^{45,46}$. We observed $\sim 95 \%$ deletion of ABCG1 in macrophages from $A b c g 1^{\mathrm{f} / \mathrm{fl}}-\mathrm{LysM}-\mathrm{Cre}^{+}$mice and $70 \%$ deletion of ABCG1 in $\mathrm{T}$ cells from $A b c g 1^{\mathrm{f} / \mathrm{fl}}-\mathrm{Lck}-\mathrm{Cre}^{+}$mice (Supplementary Fig. 4).

$\mathrm{We}^{32}$ and others ${ }^{33}$ have previously reported that ABCG1 deficiency increases proliferation of $\mathrm{CD} 4{ }^{+} \mathrm{T}$ cells. Therefore, it is possible that the impact of ABCG1 deficiency on tumour growth might be mediated directly through T-cell intrinsic mechanisms. To determine the impact of selective ABCG1 deletion in $\mathrm{T}$ cells on tumour growth, we injected MB49 tumour cells subcutaneously into Western-like diet-fed $A b c g 1^{\mathrm{fl} / \mathrm{fl}}$-Lck-Cre ${ }^{+}$ and control $A b c g 1^{\mathrm{f} / \mathrm{fl}}$-Lck-Cre ${ }^{-}$mice. The tumour growth in the $A b c g 1^{\mathrm{fl} / \mathrm{fl}}$-Lck-Cre ${ }^{+}$mice was comparable to control (Fig. 3a), indicating that the inhibition of tumour growth in the absence of ABCG1 is not mediated directly through $\mathrm{T}$ cells. However, we found that the tumour growth in $A b c g 1^{\mathrm{fl} / \mathrm{fl}}$-LysM-Cre ${ }^{+}$mice, which have selective ABCG1 deletion in myeloid cells, was 
a

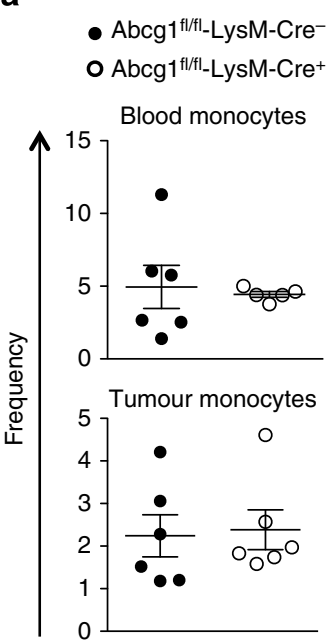

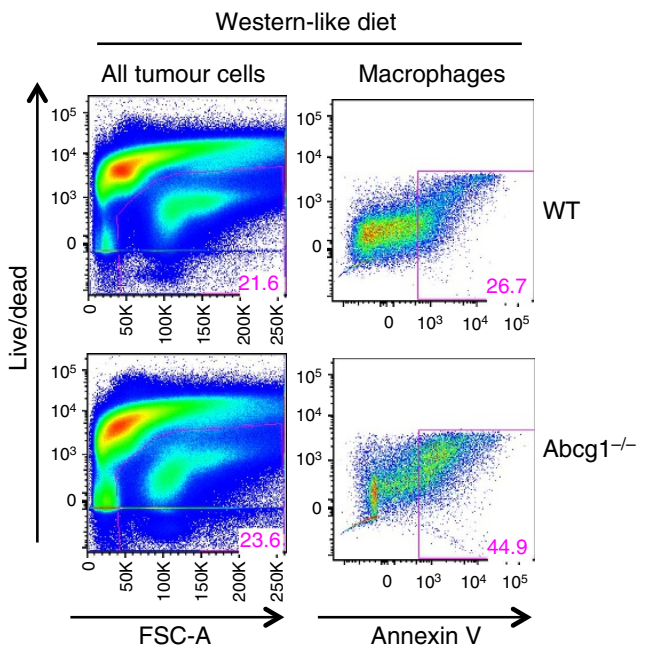

C

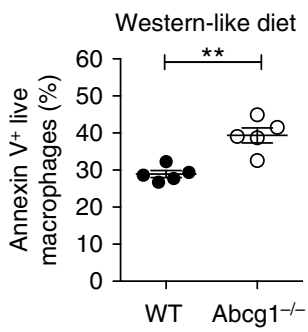

d
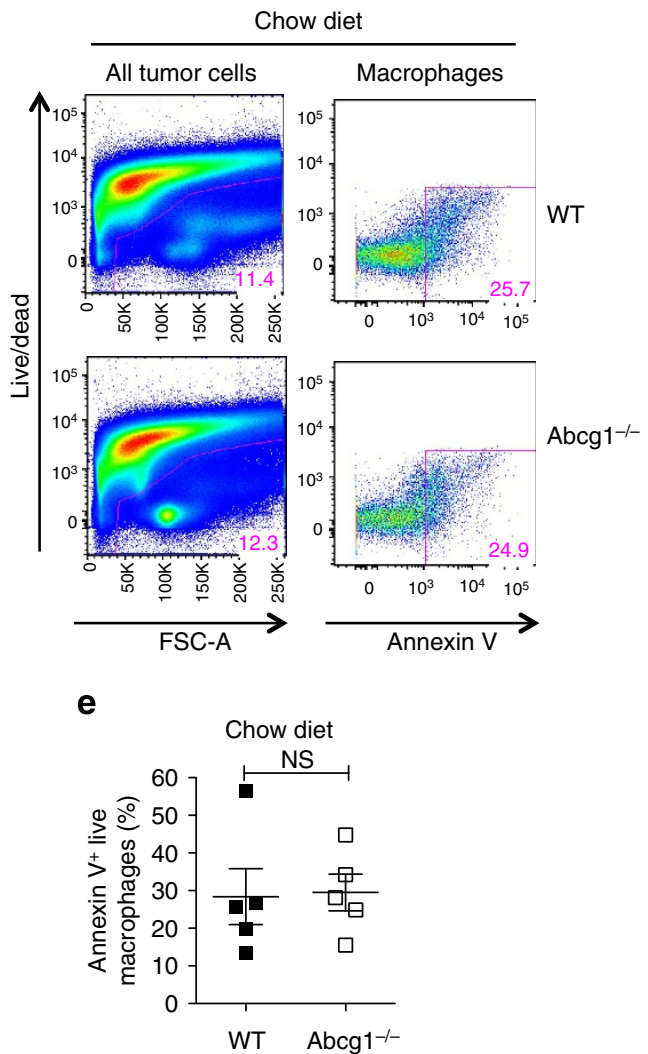

Figure 4 | Abcg1 ${ }^{-1}$ - macrophages in the tumour display enhanced apoptosis under Western-like diet conditions. (a) Blood and tumour cells

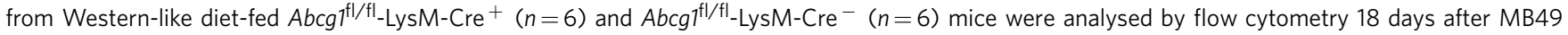

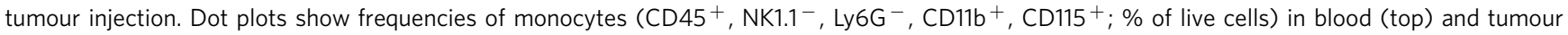
(bottom). (b-e) Tumour cells from Abcg1-/ $-(n=5)$ and WT $(n=5)$ mice were analysed for apoptosis by Annexin $V$ staining and flow cytometry 12 days after injection of MB49 cells. (b,d) Representative pseudocolour plots show percentages of all tumour cells gated on live cells (left) and CD45 ${ }^{+}, \mathrm{NK}_{1.1^{-}}$, $\mathrm{Ly}_{6 \mathrm{G}}{ }^{-}, \mathrm{CD}_{11 b^{+}}, \mathrm{F} 4 / 80^{\text {high }}$ macrophages, which are Annexin $\mathrm{V}^{+}$(right). Dot plots show the percentages of apoptotic (Annexin $\mathrm{V}^{+}$live) macrophages in tumours from (c) Western-like-diet-fed and (e) chow diet-fed mice. Data are representative of two independent experiments with similar results (mean \pm s.e.m., ${ }^{\star \star} P<0.01$, two-tailed Student's $t$-test).

dramatically reduced compared with control $A b c g 1^{\mathrm{fl} / \mathrm{fl}}$-LysM$\mathrm{Cre}^{-}$mice (Fig. 3b). These data indicate that the reduced tumour growth in the absence of ABCG1 is mediated directly through myeloid cell intrinsic mechanisms.

Subsequently, we analysed the tumour-infiltrating immune cells in MB49 tumours from Western-like diet-fed $A b c g 1^{\mathrm{fl} / \mathrm{fl}}$ LysM-Cre $^{+}$and control mice by flow cytometry. In line with the changes in the frequencies of tumour-infiltrating immune cells in Western-like diet-fed $A b c g 1^{-I}$ mice (Fig. 2c), the frequencies of tumour-infiltrating macrophages and Tregs in Abcg1 1 l/fl-LysM$\mathrm{Cre}^{+}$mice were significantly lower, whereas the frequencies of NK cells and $\mathrm{CD}_{4}^{+} \mathrm{T}$ cells were significantly higher compared with control (Fig. 3c). The frequencies of neutrophils, DCs, $\mathrm{CD}^{+}$cells and NKT cells in $A b c g 1^{\mathrm{fl} / \mathrm{fl}}$-LysM-Cre ${ }^{+}$mice and control mice were comparable (Fig. 3c). We also analysed activation markers on tumour-infiltrating immune cells. We observed that the mean fluorescence intensity (MFI) of CD69 expression on NK cells was significantly higher in $A b c g 1^{\mathrm{fl} / \mathrm{fl}}$ LysM-Cre $^{+}$mice compared with control (Fig. 3d). The MFI of CD69 expression on CD ${ }^{+}$T cells, CD8 ${ }^{+} \mathrm{T}$ cells and NKT cells, the MFI of CD86 expression on macrophages and DCs and the MFI of CD11b expression on neutrophils were similar between both genotypes (Fig. 3d). LysM-Cre mice have been shown to display Cre-mediated deletion of loxP-flanked target genes in myeloid cells; mainly in macrophages and neutrophils and partially in $\mathrm{DCs}^{46}$. In both Western-like diet-fed $A b c g 1^{-/-}$ mice and $A b c g 1^{\mathrm{fl} / \mathrm{fl}}$-LysM-Cre ${ }^{+}$mice, the frequency of macrophages was decreased, whereas no significant differences were observed in the frequencies or the activation of tumourinfiltrating neutrophils and DCs (Figs $2 \mathrm{c}$ and $3 \mathrm{c}, \mathrm{d}$ ). Therefore, our data suggest that ABCG1 deficiency in macrophages likely promotes multiple antitumour immune responses.

Impact of ABCG1 on apoptosis of tumour macrophages. Next we investigated why ABCG1 deficiency caused a reduction in the frequency of macrophages in tumours. We first measured the frequency of monocytes in blood and in tumours from $A b c g 1^{\mathrm{fl} / \mathrm{fl}}$ LysM-Cre $^{+}$and $A b c g 1^{\mathrm{fl} / \mathrm{fl}}$-LysM-Cre ${ }^{-}$mice fed a Western-like diet. The frequencies of monocytes in blood and tumours were similar in both groups (Fig. 4a), so changes in monocyte levels was not the cause. To determine if the reduction in the frequency of macrophages is due to an increase in macrophage cell death, we measured apoptosis of $A b c g 1^{-1-}$ and WT macrophages in the tumour by Annexin V staining and flow cytometry. We found that the percentage of apoptotic (Annexin $\mathrm{V}^{+}$live) macrophages in Western-like diet-fed $A b c g 1^{-I}$ mice was significantly higher compared with WT mice (Fig. 4b,c). The percentage of apoptotic macrophages in chow diet-fed $A b c g 1^{-I^{-}}$and WT mice was comparable (Fig. $4 \mathrm{~d}, \mathrm{e}$ ). These data show that macrophages in the 
tumour of $A b c g 1^{-1-}$ mice fed a Western-like diet display increased apoptosis.

Abcg1 ${ }^{-/-}$macrophages shift towards an M1 phenotype. Excess cholesterol is exported out of the cell by the cholesterol transporters ABCG1 and ABCA1 (refs 47,48). ABCG1 effluxes cholesterol to HDL particles ${ }^{23}$, while ABCA1 promotes cholesterol efflux to lipid-poor apolipoprotein AI (apoAI) ${ }^{49}$. We found that $A b c g 1^{-1-}$ macrophages expressed higher levels of Abcal compared with WT macrophages in the tumour (Supplementary Fig. 5). Subsequently, we investigated the phenotype of $A b c g 1^{-1}$ macrophages in the tumour. We analysed the expression of CD11c, which is an M1-associated marker in tumour macrophages ${ }^{50}$. We found that in Western-like diet-fed $A b c g 1^{-1-}$ mice, the percentage of $\mathrm{F} 4 / 80^{\text {high }} \mathrm{CD} 11 \mathrm{c}^{\text {high }}$ (M1-like) macrophages was approximately five times higher than $\mathrm{F} 4 / 80^{\text {high }} \mathrm{CD} 11 \mathrm{c}{ }^{\mathrm{dim}}$ (M2-like) macrophages, whereas in WT mice the percentages of both groups were similar (Fig. 5a,b). Moreover, we found that in the chow diet-fed $A b c g 1^{-1-}$ mice, the percentage of $\mathrm{F} 4 / 80^{\text {high }} \mathrm{CD} 11 \mathrm{c}^{\text {high }}$ (M1-like) macrophages was only slightly (23\%) higher than $\mathrm{F} 4 / 80^{\mathrm{high}} \mathrm{CD} 11 \mathrm{c}^{\mathrm{dim}}$ (M2-like) macrophages, whereas in WT mice the percentages of both groups were similar (Supplementary Fig. 6). This shows that although $A b c g 1^{-1-}$ macrophages display a slight shift towards an M1 phenotype (based on CD11 $\mathrm{c}^{\text {high }}$ ) even under chow diet conditions, this phenotypic shift becomes much more prominent when the mice were fed with Western-like diet. To further analyse the polarization phenotype of tumour macrophages in $\mathrm{Abcg1} 1^{-1-}$ mice, we evaluated using quantitative real-time PCR the expression of M1 markers Tnfa and Nos2 and M2 markers Arg1, Ccl22 and Mrc1 in macrophages sorted via flow cytometry from tumours from Western-like diet-fed $\mathrm{Abcgl}^{-1-}$ and WT mice. We found that the expression of Tnfa and Nos 2 was significantly higher in tumour macrophages from $A b c g 1^{-1-}$ mice (Fig. 5c), whereas the expression of Arg1, Ccl22 and Mrc1 was significantly lower in $A b c g 1^{-1-}$ macrophages compared with WT macrophages (Fig. 5d). These data point to a shift in the phenotype of macrophages in the tumours of $A b c g 1^{-1-}$ mice from tumour-promoting M2 macrophages to tumour-fighting M1 macrophages under Western-like diet conditions.

We also analysed macrophages in the spleens and lungs of Western-like diet-fed MB49 tumour-bearing $A b c g 1^{-1-}$ and WT mice by flow cytometry at day 20 . We found that $A b c g 1^{-1-}$ alveolar macrophages displayed enhanced MHC II expression compared with control, suggesting an M1 skewing. This result is consistent with the previous studies, which reported that Abcg1 $1^{-1}$ macrophages exhibited elevated proinflammatory activity in lung ${ }^{28,29}$. Although the level of MHC II expression in $A b c g 1^{-1-}$ spleen macrophages tended to be higher compared with control, it did not reach statistical significance (Supplementary Fig. 7).

Next we investigated why ABCG1-deficient macrophages shift towards an M1 phenotype in the tumour. Since we showed that $\mathrm{Abcg1} \mathrm{I}^{-1-}$ macrophages from Western-like diet-fed mice displayed increased apoptosis compared with WT macrophages (Fig. 4b,c), one possible explanation of this M1 shift could be that $A b c g 1^{-1-}$ M2 macrophages are more prone to apoptosis than Abcg1 $1^{-1-}$ M1 macrophages. To test this, we measured apoptosis of both M1 and M2 macrophages in tumours from Western-like diet-fed $A b c g 1^{\mathrm{f} / f \mathrm{l}}$-LysM-Cre ${ }^{+}$and $A b c g 1^{\mathrm{fl} / \mathrm{fl}}$-LysM-Cre ${ }^{-}$mice by Annexin V staining and flow cytometry. We found that M1 and M2 tumour macrophages from $\mathrm{Abcg} 1^{\mathrm{l} / \mathrm{fl}}$-LysM-Cre ${ }^{+}$mice displayed similarly enhanced levels of apoptosis compared with control mice (Fig. 5e). Similar results for apoptosis were obtained also with staining for active Caspase-3 (Supplementary Fig. 8). These data indicate that the shift towards M1 phenotype in the tumour on ABCG1 deficiency is not the result of M2 macrophages being more prone to apoptosis.

Next we examined if $A b c g 1^{-1-}$ macrophages are intrinsically biased towards M1 polarization. To test this, we generated bone marrow-derived macrophages (BMDMs) from $A b c g 1^{-1-}$ and WT mice and polarized them to either an M1 phenotype by interferon-gamma (IFN $\gamma$ )/LPS stimulation or to an M2 phenotype by interleukin-4 (IL-4) stimulation in vitro. First, we measured Abcg1 and Abca1 mRNA expression in polarized WT BMDMs. Both IFN $\gamma / \mathrm{LPS}$ and IL-4 stimulation significantly increased Abcg1 expression, but decreased $A b c a 1$ expression in WT macrophages (Supplementary Fig. 9). Next we determined the expression of $\mathrm{M} 1$ and $\mathrm{M} 2$ markers in polarized $A b c g 1^{-1-}$ and WT BMDMs. We found that $A b c g 1^{-}{ }^{-}$macrophages had increased production of the M1 markers tumour-necrosis factor- $\alpha(\mathrm{TNF} \alpha ; 50 \%)$ and nitric oxide (NO; 50\%) after IFN $\gamma /$ LPS stimulation compared with control (Fig. 5f). Moreover, $A b c g 1^{-1-}$ macrophages displayed enhanced expression of the M1 activation marker proteins MHC II (2.1-fold) and CD86 ( $\sim 50 \%)$ when stimulated with the M1 inducers IFN $\gamma /$ LPS (Fig. 5f). In contrast, $A b c g 1^{-1-}$ macrophages displayed decreased expression of the M2 markers Arg1 (twofold), Mrc1 (40\%) and Retnla (Fizz1; 2.3-fold) after stimulation with the M2 inducer IL-4 (Fig. 6g). Arg1 ( 20-fold) and $\mathrm{Mrcl}$ (approximately twofold) expression levels were also significantly lower in nonpolarized (unstimulated) $A b c g 1^{-1-}$ macrophages (Fig. 5g). These data indicate that $A b c g 1^{-1-}$ macrophages exhibit an intrinsic bias towards M1 polarization. Altogether these data show that the M1 shift of the $A b c g 1^{-1-}$ macrophages in the tumour is not due to increased apoptosis of M2 macrophages, but rather that $A b c g 1^{-1-}$ macrophages are biased toward M1 polarization.

$A b c g 1^{-1-}$ macrophages accumulate cholesterol and cholesterol derivatives, such as 7-ketocholesterol $(7-\mathrm{KC})^{22,51}$. To investigate if cholesterol and cholesterol derivatives have any impact on the M1 phenotype in macrophages, we incubated WT BMDMs with cholesterol and other sterols, including $7 \alpha-$ hydroxycholesterol ( $7 \alpha-\mathrm{OHC}), 25$-hydroxycholesterol (25-OHC), 27-hydroxycholesterol (27-OHC), desmosterol and 7-KC. After that, we either polarized BMDMs to an M1 phenotype by IFN $\gamma /$ LPS stimulation or left them unstimulated. We found that incubation with cholesterol or 7-KC increased the levels of M1 markers, MHC II and TNF $\alpha$ in unstimulated macrophages. Incubation with cholesterol, but not 7-KC, also increased the levels of MHC II and TNF $\alpha$ after IFN $\gamma /$ LPS stimulation (Fig. 6a,b). Incubation with $7 \alpha-\mathrm{OHC}, 25-\mathrm{OHC}, 27-\mathrm{OHC}$ or desmosterol did not significantly alter the expression of M1 markers in either unstimulated or IFN $\gamma /$ LPS- stimulated macrophages (data not shown). Thus, WT macrophages display an increase in the levels of M1 markers when incubated with cholesterol or 7-KC, suggesting that the M1-bias in $A b c g 1^{-1-}$ macrophages is likely due to the accumulation of these sterols.

To better understand why $A b c g 1^{-1-}$ macrophages exhibit an intrinsic bias towards M1 polarization, we examined the activation of the transcription factor NF- $\mathrm{kB}$, which is well established as playing a critical role in the induction of proinflammatory gene expression in macrophages ${ }^{52}$ Phosphorylation of $\mathrm{p} 65$ subunit of NF- $\mathrm{KB}$ helps stabilize NF- $\mathrm{\kappa B}$ in the nucleus for gene transcription ${ }^{53}$ and thereby is widely used as an indicator of NF- $\mathrm{KB}$ activation. We evaluated the levels of NF-kB p65 (Ser 529) phosphorylation in unstimulated Abcg1- Iand WT BMDMs by flow cytometry. Abcg1 $1^{-1-}$ macrophages showed an $\sim 50 \%$ higher level of p65 phosphorylation compared with WT macrophages (Fig. 6c,d), indicating that the absence of ABCG1 results in an increased NF- $\mathrm{KB}$ activation in macrophages, which is a likely cause for the observed M1 phenotype bias. 
a

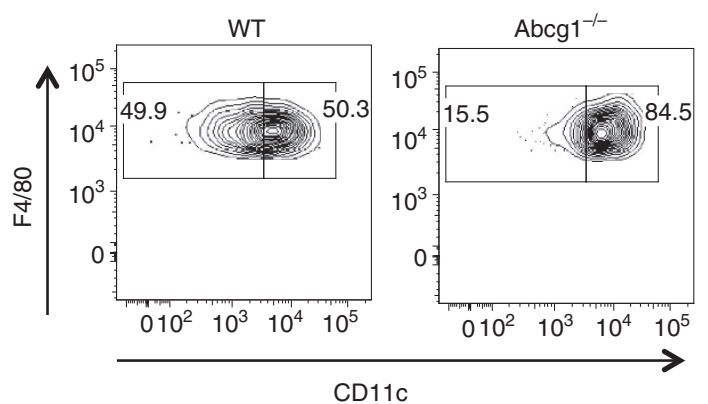

C

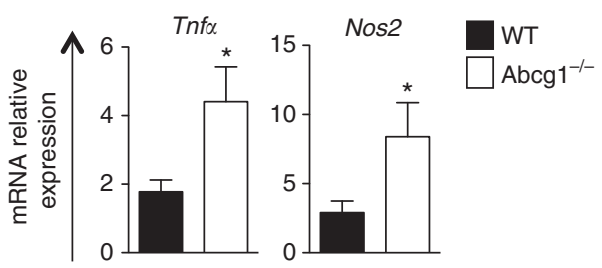

d

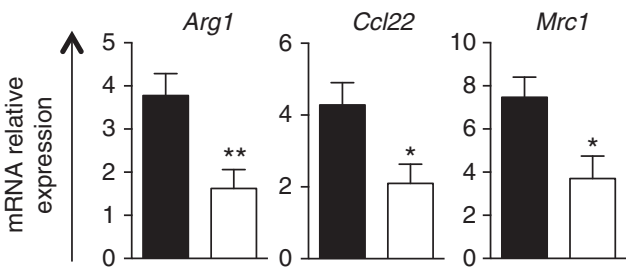

b

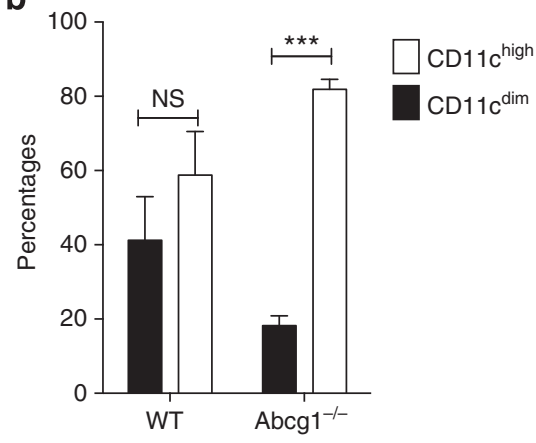

e

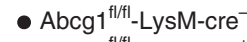

o $A$ bcg $1^{\text {fl/fI- }- \text { LysM-cre }}$

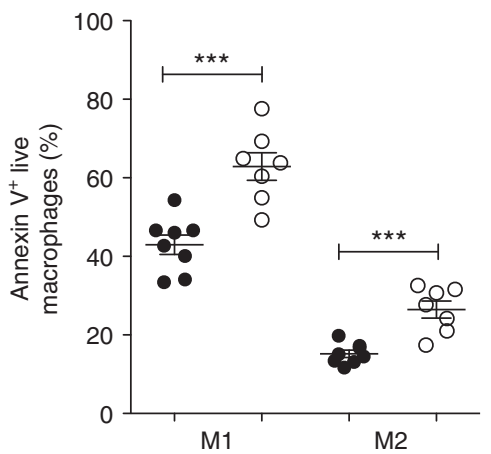

MHC-II

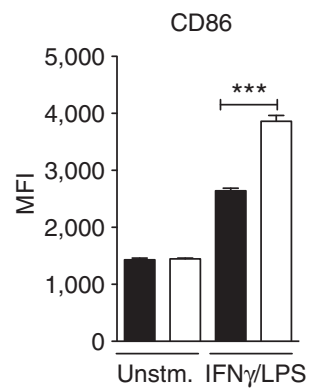

g
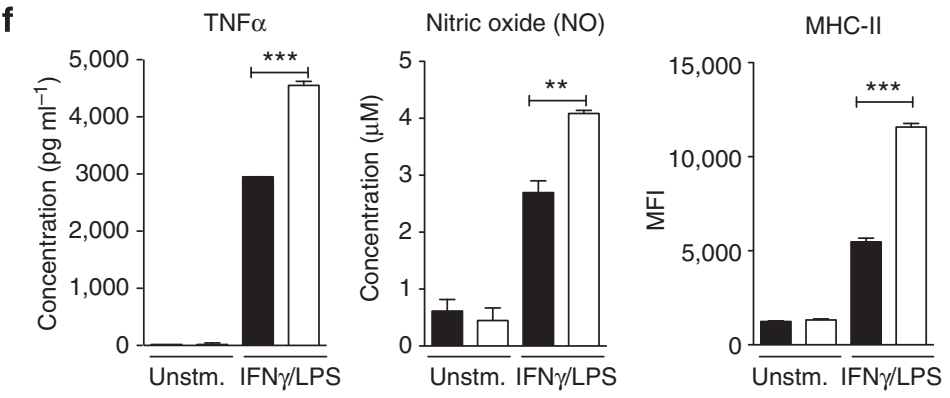

Retnla (Fizz1)
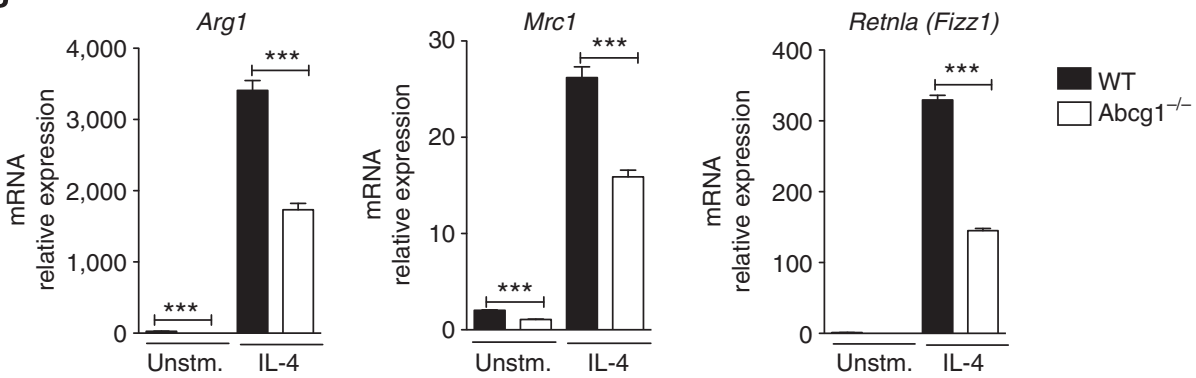

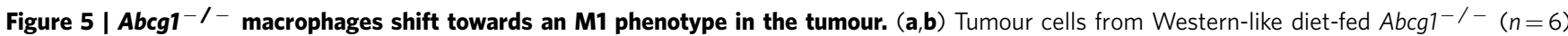
and WT mice $(n=6)$ mice were analysed by flow cytometry 20 days after injection of MB49 cells. (a) Representative contour plots and bar graphs

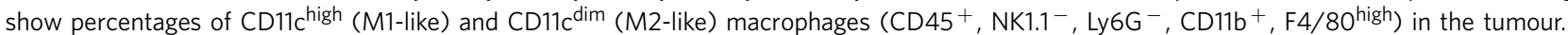

(c,d) Macrophages were fluorescence-activated cell sorted from tumours from Western-like diet-fed Abcg ${ }^{-1}-$ and WT mice 20 days after inoculation of MB49 cells. Expression of (c) M1 markers Tnf $\alpha$ and Nos2 and (d) M2 markers Arg1, Ccl22, Mrc1 were measured by quantitative real-time PCR (qPCR).

(e) Tumour cells from Western-like diet-fed Abcg fl/fl-LysM-Cre ${ }^{+}(n=7)$ and $A b c g 7^{f l / f l}-$ LysM-Cre $-(n=8)$ mice were analysed for apoptosis by Annexin $\mathrm{V}$ staining and flow cytometry 12 days after injection of MB49 cells. Dot plot shows percentages of apoptotic (Annexin $\mathrm{V}^{+}$live) M1 (CD11chigh) and M2 $\left(\right.$ CD11 $\left.\mathrm{c}^{\mathrm{dim}}\right)$ macrophages in the tumour. Data are pooled from two independent experiments with similar results. (f,g) WT and Abcg1-/- BMDMs were polarized to an M1 phenotype by IFN $\gamma /$ LPS stimulation or to an M2 phenotype by IL-4 stimulation, in vitro. Expression of (f) M1 markers and (g) M2 markers were analysed by enzyme-linked immunosorbent assay (ELISA) (TNF $\alpha$ ), Griess reagent system (NO), flow cytometry (MHC II, CD86) or qPCR (Arg1, Mrc1, Retnla). Data are representative of two independent experiments with similar results (mean \pm s.e.m., ${ }^{\star} P<0.05$, ${ }^{\star \star} P<0.01,{ }^{\star \star \star} P<0.001$, twotailed Student's t-test). Unstim., unstimulated. 
a
Cholestero

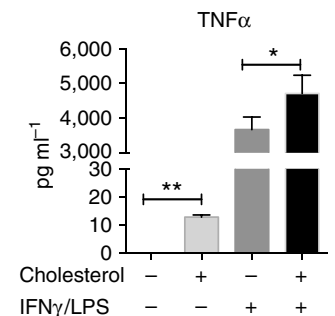

b

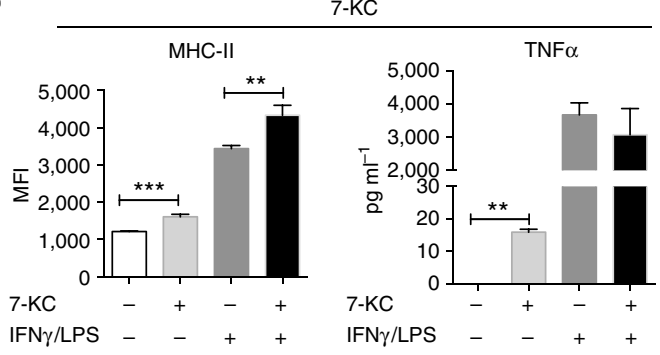

C

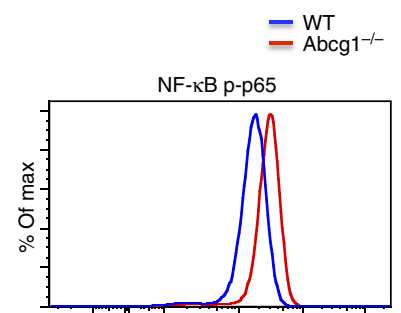

d

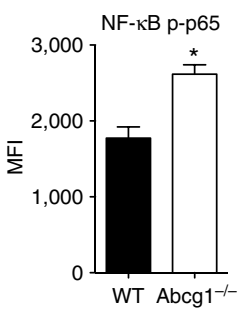

Figure 6 | Cholesterol and 7-KC stimulation increase expression of M1 markers in macrophages. (a,b) WT BMDMs were preincubated with cholesterol $\left(20 \mu \mathrm{g} \mathrm{ml}^{-1}\right)$ or $7-\mathrm{KC}(5 \mu \mathrm{M})$ for $2 \mathrm{~h}$. After that, the cells were stimulated with IFN $\gamma\left(20 \mathrm{ng} \mathrm{ml}^{-1}\right)$ and LPS $\left(100 \mathrm{ng} \mathrm{ml}^{-1}\right)$ or left unstimulated as described in the Methods. MHC II expression was analysed by flow cytometry and TNF $\alpha$ production was analysed by enzyme-linked immunosorbent assay. (c) Representative plot and (d) graph show levels of NF- KB p65 phosphorylation (Ser 529) in Abcg1-/- and WT BMDMs analysed by flow cytometry. Data are representative of two independent experiments with similar results. (mean \pm s.e.m., ${ }^{\star} P<0.05$, ${ }^{\star \star} P<0.01$, ${ }^{\star \star \star} P<0.001$, two-tailed Student's $t$-test).

Abcg1 $1^{-/-}$macrophages show enhanced tumour cytotoxicity. Next we investigated how the shift of macrophages towards an M1 phenotype in the absence of ABCG1 reduces tumour growth. M2-like TAMs support tumour growth through various mechanisms including promoting angiogenesis ${ }^{6-9}$ Therefore, ABCG1 deficiency might decrease the ability of macrophages to promote tumour angiogenesis. To test this, we assessed the expression levels of endothelial cell markers in tumours from $A b c g 1^{\mathrm{fl} / \mathrm{fl}}$-LysM-Cre ${ }^{+}$and $A b c g 1^{\mathrm{fl} / \mathrm{fl}}$-LysM-Cre ${ }^{-}$mice by flow cytometry. We found comparable levels of $\mathrm{CD}_{4}{ }^{-} \mathrm{CD} 31^{+}$ $\mathrm{CD}_{3}{ }^{+}$vascular endothelial cells in tumours from both mice groups (Fig. 7a,b), indicating that ABCG1-deficient macrophages are similar to WT macrophages in terms of promoting tumour angiogenesis, making this an unlikely mechanism.

Unlike M2-like TAMs, M1 macrophages can be cytotoxic to tumour cells and, in this way, can prevent tumour growth ${ }^{54}$. To investigate if the impact of ABCG1 deficiency on tumour growth can be through increased ability of macrophages to kill tumour cells directly, we performed an in vitro cytotoxicity assay. In brief, we polarized bone marrow-derived $A b c g 1^{-1}$ and WT macrophages to M1 phenotype by IFN $\gamma /$ LPS stimulation and cocultured these M1 macrophages with MB49 tumour cells. We assessed the viability of tumour cells by flow cytometry. We found that the frequency of dead tumour cells (CD45 ${ }^{-} \mathrm{F} 4 / 80^{-}$ $7-\mathrm{AAD}^{+}$) was $40 \%$ higher when they were co-cultured with Abcg1-1- macrophages, compared with WT macrophages (Fig. 7c,d). This indicates that $A b c g 1^{-1-}$ macrophages display enhanced cytotoxicity for tumour cells, making this a likely explanation for the reduced tumour growth observed in vivo.

\section{Discussion}

In this study, we identify a novel role for the cholesterol transporter ABCG1 as a modulator of tumour immunity. The absence of ABCG1 inhibits tumour growth through the modulation of macrophage survival and phenotype within the tumour. Collectively, our data demonstrate an important new concept that cholesterol homeostasis in immune cells can determine the outcome of tumour growth in vivo.

LysM-Cre mice have been shown to display Cre-mediated deletion of loxP-flanked target genes in myeloid cells, mainly in macrophages and neutrophils and partially in $\mathrm{DCs}^{46}$. In tumours from Western-like diet-fed $A b c g 1^{-/-}$mice and $A b c g 1^{\mathrm{fl} / \mathrm{fl}}$-LysM$\mathrm{Cre}^{+}$mice, the frequency of macrophages was reduced, while the frequencies and the activation of neutrophils and DCs were similar compared with control (Figs $2 c$ and $3 c, d$ ). Moreover, we showed that ABCG1-deficient macrophages exhibit an intrinsic bias toward tumour-fighting M1 polarization and display enhanced ability to kill tumour cells directly (Fig. 7c,d). Therefore, we conclude that the reduced tumour growth in the absence of ABCG1 is mediated through macrophage-intrinsic mechanisms.

Increased apoptosis of $A b c g 1^{-1-}$ macrophages was also reported in atherosclerosis studies in mice, in which increased numbers of apoptotic macrophages were found within atherosclerotic lesions of Western-like diet-fed $A b c g 1^{-1-} A p o E^{-/-}$ mice and $L d l r^{-1-}$ mice transplanted with $A b c g 1^{-}-$bone marrow ${ }^{26,27}$. In addition, $A b c g 1^{-I-}$ macrophages have been shown to undergo apoptosis after a challenge with oxLDL ${ }^{26,51}$ in vitro. Increased apoptosis of ABCG1-deficient macrophages is a result of the accumulation of specific toxic oxysterols, including $7-\mathrm{KC}$, which are known to induce apoptosis ${ }^{27,51}$. 7-KC and related oxysterols have been shown to be selectively exported out of the cell by ABCG1, but not by ABCA1 (ref. 51). Furthermore, the observed shift of $A b c g 1^{-I}$ macrophages in the tumour towards a proinflammatory M1 phenotype (Fig. 5a-d) is in concordance with a previous study in atherosclerosis, which reported that macrophages from $A b c g 1^{-1-}$ mice fed a Westernlike/high-cholesterol diet exhibited elevated proinflammatory activity $^{31}$. Macrophages are known to accumulate cholesterol in the absence of ABCG1 (ref. 22). Our data demonstrate that macrophages display an increase in the levels of M1 markers when incubated with cholesterol or 7-KC (Fig. 6a,b), suggesting 
a

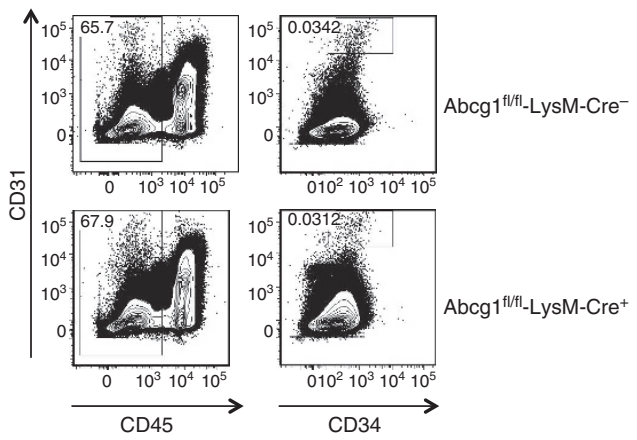

b

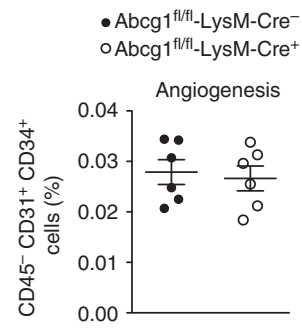

C

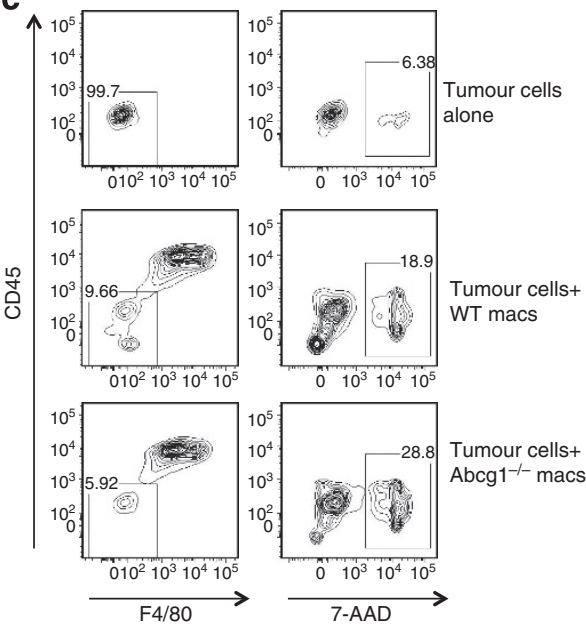

d

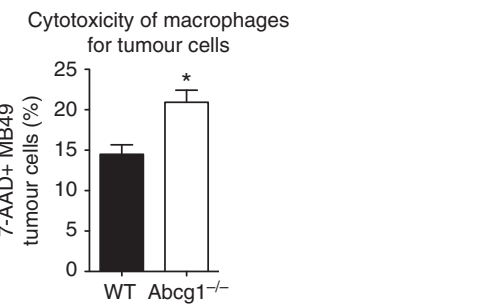

Figure 7 | $\mathbf{A b c g} \mathbf{1}^{-1}$ - macrophages display enhanced cytotoxicity for tumour cells. (a,b) Tumour cells from Western-like diet-fed Abcg $7^{f l / f l}-$ LysM-Cre $^{+}$ $(n=6)$ and $A b c g 7^{f l / f l}$-LysM-Cre ${ }^{-}(n=6)$ mice were analysed for angiogenesis markers by flow cytometry 18 days after injection of MB49 cells. (a) Representative contour plots and (b) dot plot show percentages of CD45-, CD31 ${ }^{+}$and $\mathrm{CD} 34^{+}$vascular endothelial cells in the tumour. (c,d) Cytotoxicity of macrophages for tumour cells was analysed by flow cytometry (See Methods). (c) Representative contour plots and (d) bar graph show percentages of $\mathrm{CD}_{4} 5^{-}, \mathrm{F} 4 / 80^{-}, 7-\mathrm{AAD}^{+} \mathrm{MB} 49$ tumour cells. Data are representative of two independent experiments with similar results (mean \pm s.e.m., ${ }^{\star} P<0.05$, two-tailed Student's $t$-test).

that the M1-bias in $\mathrm{Abcg1} 1^{-1-}$ macrophages is likely due to the excess sterol accumulation. In addition, similar to a previous report, which showed enhanced content of nuclear NF- $\mathrm{KB}$ p65 in $A b c g 1^{-1-}$ peritoneal macrophages after LPS stimulation ${ }^{30}$, we observed elevated NF- $\mathrm{\kappa B}$ p65 phosphorylation in $A b c g 1^{-1-}$ BMDMs (Fig. $6 \mathrm{c}$,d). A previous study by Li et al..$^{55}$ reported that free cholesterol accumulation in macrophages induced the production of proinflammatory cytokines through the activation of I $\kappa$ B kinase/NF- $\kappa B$ pathway. Therefore, based on our data, we surmise that an increased cholesterol accumulation in macrophages in the absence of ABCG1 causes NF- $\mathrm{KB}$ activation, which polarizes these macrophages to a proinflammatory/ tumour-fighting M1 phenotype. M1 macrophages produce TNF $\alpha$ and NO, which can mediate cytolysis of tumour cells ${ }^{54}$. Thus, the enhanced production of $\mathrm{TNF} \alpha$ and $\mathrm{NO}$ in $A b c g 1^{-1-} \mathrm{M} 1$ macrophages that we reported here (Fig. $5 c, f)$ is likely the cause of the observed increase in direct cytotoxicity of $A b c g 1^{-1-}$ macrophages for tumour cells (Fig. $7 \mathrm{c}, \mathrm{d}$ ).

In most tumour models, the majority of the macrophages in tumours display a tumour-promoting M2 phenotype ${ }^{5}$. Our study shows that ABCG1 deficiency not only reduces the number of macrophages within the tumour, but also causes a shift of the remaining macrophages to a tumour-fighting M1 phenotype. Therefore, ABCG1 may constitute a therapeutic target for cancer.

TAMs can promote tumour growth by different mechanisms. Production of CCL22 by immunosuppressive TAMs has been shown to recruit tumour-promoting Tregs to the tumour site ${ }^{10}$. Thus, our observation of reduced Treg frequency in the tumour in the absence of ABCG1 could be explained by a reduction in the frequency of TAMs (Figs $2 \mathrm{c}$ and $3 \mathrm{c}$ ) and a phenotypic shift of the remaining TAMs to M1 macrophages, which are not potent
CCL22 producers (Fig. 5c,d). Tregs suppress the expansion of antitumour effector cells including NK cells and CD4 ${ }^{+} \mathrm{T}$ cells ${ }^{10}$. Therefore, our observation of an increase in the frequency of NK cells and $\mathrm{CD} 4^{+} \mathrm{T}$ cells in the absence of ABCG1 could be explained by a decrease in the frequency of Tregs in the tumour (Figs $2 \mathrm{c}$ and $3 \mathrm{c}$ ). Our data support the notion that M1 phenotypic shift of $A b c g 1^{-1}$ macrophages with reduced CCL22 production results in reduced Treg recruitment, which in turn increases tumour infiltration by NK cells and $\mathrm{CD} 4{ }^{+} \mathrm{T}$ cells. Since these cells are well-established tumour-fighting cells ${ }^{1}$, an increase in their frequency would have an impact on tumour growth. Collectively, our data support the concept that the absence of ABCG1 in macrophages drives changes in macrophage-intrinsic cytokine production and as such, could increase NK cell and $\mathrm{CD} 4^{+}$T-cell infiltration into the tumour to further prevent tumour growth.

Our study suggests that intrinsic loss of ABCG1 in macrophages is of critical importance for the mechanisms behind the effects on tumour growth. Our data support the notion that accumulation of cholesterol in macrophages in the absence of ABCG1 impacts their survival and phenotype, thus changing their function in the tumour. Since $A b c g 1^{-1-}$ macrophages cannot efflux cholesterol properly, more cholesterol accumulates in $A b c g 1^{-1-}$ macrophages compared with WT macrophages, which has been well documented ${ }^{22}$. In young $A b c g 1^{-/-}$ mice, macrophage cholesterol accumulation is accelerated by Western-like diet feeding or by crossing the mice onto a hypercholesterolemic mouse model background. However, our finding that aged $\mathrm{Abcg} 1^{-1-}$ mice display reduced tumour growth when fed a chow diet supports the notion that macrophages in older $A b c g 1^{-1-}$ mice accumulate more 
cholesterol over time ${ }^{44}$. Thus, in the aged $A b c g 1^{-1-}$ mice, the tumour phenotype becomes evident even on a chow diet.

Enhanced expression of ABCG1 but reduced expression of ABCA1 after LPS/IFN $\gamma$ or IL-4 stimulation in WT macrophages (Supplementary Fig. 9) point to an importance of ABCG1 in macrophage activation. Increased expression of ABCA1 in Abcg1 $1^{-1-}$ TAMs is not surprising (Supplementary Fig. 5), since $\mathrm{we}^{32,34}$ and others ${ }^{36,56}$ have previously shown that genetic deletion of one cholesterol transporter, either ABCG1 or $A B C A 1$, is compensated for by an upregulation of the other transporter. Nevertheless, neither ABCG1 nor ABCA1 can fully compensate for the loss of the other ${ }^{20}$. However, we cannot rule out the possibility that changes in $\mathrm{ABCA} 1$ expression contributed to our observed findings of reduced tumour growth in $A b c g 1^{-1-}$ mice. Future studies using ABCA1-deficient mice will be useful to delineate the roles of these two transporters in tumour immunity.

From many perspectives, atherosclerosis and cancer are fundamentally different. However, the immune system plays a major role in the progression of both diseases. Human population and animal studies clearly demonstrate that HDL protects against atherosclerosis ${ }^{57}$. Interestingly, meta-analysis of lipid-altering therapies has indicated an inverse relationship between plasma HDL levels and incidence of cancer ${ }^{58}$. In concordance with this report, a recent study has shown that apoAI, the major protein component of HDL, suppresses tumour growth and metastasis in mice via the modulation of immune responses ${ }^{59}$. Collectively, these studies suggest that HDL has a role both in atherosclerosis and cancer. ABCG1 deficiency in immune cells has been shown to protect mice from atherosclerosis development ${ }^{26,36}$. By demonstrating that myeloid cell-specific ABCG1 deletion suppresses tumour growth, our present study suggests that ABCG1 might link immunity in atherosclerosis and cancer.

In sum, our study identifies ABCG1 as a novel mediator of antitumour immune responses. It defines an important role for cholesterol transporters in tumour immunity and provides a link between lipid homeostasis and cancer. Understanding how ABCG1 and cholesterol metabolism in immune cells impacts antitumour immune responses could lead to development of entirely new therapeutic approaches for cancer immunotherapy.

\section{Methods}

Mice. C57BL/6J mice (000664), $\mathrm{Ldlr}^{-/-}$mice (002207) and $A p o E^{-/-}$mice (002052) were purchased from The Jackson Laboratory (Bar Harbor, ME) $A b c g 1^{-1-/ l a c Z}$ knock-in mice were purchased from Deltagen (San Mateo, CA) and are congenic to a C57BL/6J background (backcrossed 14 generations). B6.SJL-Ptprca/BoyAiTac mice (CD45.1 congenic, 004007) were purchased from Taconic Farms (Germantown, NY). Abcg1 ${ }^{-1}$ mice were crossed with $L d l r^{-1}$ and $A p o E^{-I-}$ mice to obtain $A b c g 1^{-1-} \mathrm{Ldlr}^{-1-}$ and $\mathrm{Abcg1^{-/- }} A \mathrm{poE} \mathrm{E}^{-/-}$ mice, respectively. Conditional knockout $A b c g 1^{\mathrm{fl} / \mathrm{fl}}$ mice (C57BL/6J background) in which loxP sites flank the Walker domain of exon 3 of $A b c g 1$ were generated for our laboratory using InGenious Targeting Laboratory (New York). An 10.3-kb region used to construct the targeting vector was first subcloned from a positively identified BAC clone using homologous recombination. The region was designed such that the short homology arm extends $2.2 \mathrm{~kb} 5^{\prime}$ to lox P/FRT-flanked Neo cassette. The long homology arm ends on the $3^{\prime}$ side of lox P/FRT-flanked Neo cassette and is $\sim 8.1-\mathrm{kb}$ long. The single lox $\mathrm{P}$ site is inserted upstream of exon 3 , and the lox P/FRT-flanked Neo cassette is inserted downstream of exon 3 . The target region is $1.5 \mathrm{~kb}$ including exon 3 . The targeting vector is confirmed by restriction analysis after each modification step and by sequencing using primers designed to read from the selection cassette into the $3^{\prime}$ end of the long homology arm (N7) and the $5^{\prime}$ end of the short homology arm (N1), or from primers that anneal to the vector sequence, P6 and T7, and read into the $5^{\prime}$ and $3^{\prime}$ ends of the $\mathrm{BAC}$ sub clone. $A b c g 1^{\mathrm{fl} / \mathrm{fl}}$ mice were crossed with Lck-Cre mice $(003802$, The Jackson Laboratory) to obtain $A b c g 1^{\mathrm{fl} / \mathrm{fl}}$-Lck-Cre ${ }^{+}$and control $A b c g 1^{\mathrm{f} / \mathrm{fl}}$-Lck-Cre mice, and crossed with LysM-Cre mice (004781, The Jackson Laboratory) to obtain $A b c g 1^{\mathrm{fl} / \mathrm{fl}}$-LysM-Cre ${ }^{+}$and $\mathrm{Abcg} 1^{\mathrm{fl} / \mathrm{fl}}$-LysM-Cre ${ }^{-}$mice. All the mice used in this study were female and 7-10 weeks old, except for the tumour growth experiment in the aged $A b c g 1^{-1-}$ and C57BL/6 (WT) mice, which were 6-7 months old. Mice were fed a standard rodent chow diet containing $0 \%$ cholesterol and $5 \%$ calories from fat (Pico lab, \#5053) or Western-like diet containing $0.2 \%$ cholesterol and
42\% calories from fat (Harlan Laboratories, \#TD88137). The mice were housed in microisolator cages in a pathogen-free animal facility of the La Jolla Institute for Allergy and Immunology.

The plasma lipid profile analyses were performed at day 12 , because this is the very earliest time that significant differences were observed in tumour growth. Day 12 is also the time when differences in macrophage apoptosis were observed, which then later on leads to a more prominent difference in tumour growth. Tumour growth was measured until days 18-20 and that is the time when the frequency and phenotype of the immune cells within the tumour were analysed.

All the experiments followed the guidelines of the La Jolla Institute for Allergy and Immunology Animal Care and Use Committee and approval for use of rodents was obtained from the La Jolla Institute for Allergy and Immunology according to criteria outlined in the Guide for the Care and Use of Laboratory Animals from the National Institutes of Health. Mice were euthanized by $\mathrm{CO}_{2}$ inhalation.

Cell lines and reagents. MB49-bladder carcinoma and B16-F1 melanoma cells were derived from C57BL/6 mice and obtained from American Type Culture Collection. The B16-F10-luc2 cell line was established by Caliper Life Sciences by transduction of lentivirus containing luciferase 2 gene under the control of human ubiquitin $\mathrm{C}$ promoter. Tumour cells were cultured in R5 medium containing RPMI 1640, 5\% heat-inactivated fetal bovine serum, $50 \mathrm{U} \mathrm{ml}^{-1}$ penicillin and $50 \mu \mathrm{g} \mathrm{ml}^{-1}$ streptomycin. Cells were injected into mice after reaching $60-80 \%$ confluency.

Flow cytometry antibodies including anti-mouse APC-F4/80 (BM8; 1/100), FITC-Ly6G (RB6-8C5; 1/200), APC/Cy7 or AF700-CD45 (30-F11; 1/200), AF700-CD45.2 (104; 1/200), PerCP/Cy5.5-NK1.1 (PK136; 1/100), e-Fluor 450CD4 (RM4-5; 1/200), FITC-TCR $\beta$ (H57-597; 1/400), PE-CD25 (PC61.5; 1/100), APC-Foxp3 (FJK-16s; 1/100), AF700-CD34 (RAM34; 1/200) and e-Fluor 450MHC II (M5/114.15.2; 1/200), were purchased from eBioscience (San Diego, CA); PE-Cy7-CD11b (M1/70; 1/800), PE-CD11c (HL3; 1/300), FITC-CD45.1 (A20; 1/200), APC/Cy7-CD8 $\alpha$ (53-6.7; 1/200), PE-Cy7-CD69 (H1.2F3; 1/400), PE-CD31 (MEC 13.3; 1/300) and PE-phospho-p65 (S529; K10-895.12.50; 1/10), were purchased from BD Biosciences (San Jose, California); PerCP/Cy5.5-CD19 (6D5; 1/100), PE-CD115 (AFS98; 1/100) and AF700-CD86 (GL-1; 1/200) were purchased from Biolegend (San Diego, CA). CD16/CD32 (2.4G2; 1/200) antibody was purchased from BD Biosciences. Ultrapure LPS (Escherichia coli 0111:B4) was purchased from InvivoGen (San Diego, CA), murine rIFN $\gamma$ and rIL-4 were purchased from R\&D Systems (Minneapolis, MN), murine macrophage colonystimulating factor (M-CSF) was purchased from PeproTech (Rocky Hill, NJ) and RPMI 1640 medium was purchased from Invitrogen (Carlsbad, CA). Fetal bovine serum, Collagenase IV, water-soluble cholesterol, $7 \alpha-\mathrm{OHC}, 25-\mathrm{OHC}, 27-\mathrm{OHC}$, desmosterol and 7-KC were purchased from Sigma-Aldrich (St Louis, MO). DNase I was purchased from Roche (Basel, Switzerland), PBS was purchased from Thermo Scientific (Rockford, IL) and Ficoll-Paque plus was purchased from GE Healthcare (Pittsburgh, PA).

Measurement of tumour growth/metastasis and survival. MB49 or B16-F1 cells $\left(10^{5}\right)$ in $100 \mu \mathrm{l}$ PBS were injected subcutaneously into the right flanks of female age-matched 7-10-week-old $A b c g 1^{-1-}$, C57BL/6 (WT), Abcg1-1$L d l r^{-/-}, L_{d l r^{-I-}}, A b c g 1^{-/-} A p o E^{-/-}, A p o E^{-/-}, A b c g 1^{\text {fl/fl }}$-Lck-Cre ${ }^{+}$, $A b c g 1^{\mathrm{fl} / \mathrm{fl} \text {-Lck-Cre }^{-},{ }_{\text {L }} b c g 1^{\mathrm{fl} / \mathrm{fl}} \text {-LysM-Cre }}{ }^{+}$and $A b c g 1^{\mathrm{fl} / \mathrm{fl}}$-LysM-Cre ${ }^{-}$mice or 6-7-month-old $A b c g 1^{-I-}$ and WT mice. Mice were fed with either Western-like diet or chow diet beginning a week before injection of tumour cells. Tumour diameters were measured using a digital caliper and tumour volume was calculated using the formula $V=D \times d^{2} / 2$, where $V$ is the tumour volume, $D$ is the largest measured tumour diameter and $d$ is the smallest measured tumour diameter. For the survival experiments, the mice with tumour volume reaching $2,000 \mathrm{~mm}^{3}$ were considered as dead and euthanized. To measure spontaneous lung metastasis, $10^{5}$ luciferase-expressing B16-F10 cells (B16-F10-luc2) in $100 \mu$ l PBS were injected into female age-matched $\mathrm{Abcg1} \mathrm{I}^{-/-}$and C57BL/6 mice subcutaneously. Mice were fed with Western-like diet beginning a week before injection of tumour cells. B16-F10 luc2 tumours grow more aggressively than B16-F1 tumours, which allowed us to choose mice for study that had similar-sized tumours. At 28 days after B16-F10luc2 tumour inoculation, mice with similar, but average, tumour sizes in both groups were anaesthetized by inhalation of isoflurane (Butler Animal Health Supply) and $1 \mathrm{mg}$ D-Luciferin (Caliper Life Sciences, Waltham, MA) in $100 \mu \mathrm{l}$ PBS was delivered into each mouse retro-orbitally. Mice were euthanized 2 min after DLuciferin injection, lungs were harvested and lung metastases were measured using an IVIS 200 Bioluminescence Imager (Caliper Life Sciences, Hopkinton, MA).

Measurement of plasma lipoproteins. Mice were fed with either chow diet or Western-like diet beginning a week before injection of tumour cells. Blood (in EDTA) was collected from chow diet-fed or Western-like diet-fed mice 12 days after MB49 tumour inoculation. Plasma lipoprotein profiles were obtained by fast protein liquid chromatography as described previously ${ }^{60,61}$. In brief, equal volumes of plasma from five mice per group were pooled and $200 \mu \mathrm{l}$ of this pooled plasma was applied to a set of 2 Superose 6 (HR 10/30) columns linked in series. Lipoproteins were eluted by size exclusion into $0.5-\mathrm{ml}$ fractions in EDTA/NaCl/ NaN3 $\left(1 \mathrm{mmoll}^{-1} ; 0.154 \mathrm{moll}^{-1} ; 0.02 \%\right)$ at a flow rate of $0.5 \mathrm{ml} \mathrm{min}^{-1}$. 
Cholesterol was measured in each fraction using an enzymatic cholesterol kit (Wako) according to the manufacturers' instructions.

Generation of bone marrow chimeras. Recipient B6.SJL mice were irradiated in two doses of $500 \mathrm{rad}$ each (for a total of 1,000 rad) $4 \mathrm{~h}$ apart. Bone marrow cells from both femurs and tibias of B6.SJL (CD45.1) and Abcg1-1- (CD45.2) donor mice were collected under sterile conditions. Bones were centrifuged for the collection of marrow and the cells were washed and resuspended in PBS for injection. Bone marrow cells $\left(10^{7}\right)$ from B6.SJL or $A b c g 1^{-/-}$mice in $200 \mu$ PBS were delivered retro-orbitally into each recipient mouse. Recipient mice were housed in a barrier facility under pathogen-free conditions and were provided autoclaved acidified water with antibiotics (trimethoprim-sulfamethoxazole) and were fed autoclaved food. The chimeric mice were fed with Western-like diet starting 6 weeks after bone marrow reconstitution.

Flow cytometry. Tumours were meshed through a $100-\mu \mathrm{m}$ strainer (Fisher Scientific, Pittsburg, PA) and then filtered through a $40-\mu \mathrm{m}$ strainer. Single-cell suspension was resuspended in $100 \mu \mathrm{l}$ flow cytometry staining buffer ( $1 \%$ bovine serum albumin plus $0.1 \%$ sodium azide in PBS). Fcy receptors were blocked with CD16/32-blocking antibody for $10 \mathrm{~min}$ and surface antigens on cells were stained for $30 \mathrm{~min}$ at $4{ }^{\circ} \mathrm{C}$. LIVE/DEAD Fixable Dead Cell Stain (Invitrogen) was used for analysis of viability, and forward- and side-scatter parameters were used for exclusion of doublets from analysis. Antibody clones and dilutions used are listed above. For intracellular staining, cells were fixed and permeabilized with the Cytofix/Cytoperm Fixation/Permeabilization Solution Kit (BD Biosciences; for cytoplamis proteins) or Foxp3 Staining Buffer Set (eBioscience; for nuclear proteins) after the cell surface staining. Cells were stained with directly conjugated fluorescent of Foxp3 antibody for $30 \mathrm{~min}$ at $4{ }^{\circ} \mathrm{C}$ and with directly conjugated fluorescent of NF-KB phospho-p65 (Ser 529) antibody for $30 \mathrm{~min}$ at RT. Apoptosis of macrophages in tumour was measured by flow cytometry using a PE Annexin V Apoptosis Detection Kit 1 or a FITC active Caspase-3 Apoptosis Kit (BD Biosciences) according to the manufacturer's instructions.

Cell fluorescence was assessed using LSR-II (BD Biosciences) and data were analysed with FlowJo software (TreeStar, Ashland, OR). Macrophages (CD45 ${ }^{+}$, $\left.\mathrm{NK} 1.1^{-}, \mathrm{Ly}_{6 \mathrm{G}}{ }^{-}, \mathrm{CD} 11 \mathrm{~b}{ }^{+}, \mathrm{F} 4 / 80^{\text {high }}\right)$, neutrophils $\left(\mathrm{CD} 45^{+}, \mathrm{NK} 1.1^{-}, \mathrm{Ly} \mathrm{G}^{+}\right.$, $\mathrm{CD}_{11 \mathrm{~b}^{+}}$), myeloid DCs $\left(\mathrm{CD} 45^{+}, \mathrm{NK}_{1.1}^{-}, \mathrm{Ly}^{-} \mathrm{G}^{-}, \mathrm{F} 4 / 80^{-}, \mathrm{CD}_{11 \mathrm{~b}}{ }^{+}\right.$ $\left.\mathrm{CD}_{11 \mathrm{c}^{+}}\right)$, monocytes $\left(\mathrm{CD} 45^{+}, \mathrm{NK}_{1.1^{-}}, \mathrm{Ly}_{6 \mathrm{G}}{ }^{-}, \mathrm{CD} 11 \mathrm{~b}^{+}, \mathrm{CD} 115^{+}\right), \mathrm{NK}$ cells $\left(\mathrm{CD} 45^{+}, \mathrm{TCR}^{-}, \mathrm{NK} 1.1^{+}\right), \mathrm{CD} 4^{+} \mathrm{T}$ cells $\left(\mathrm{CD} 45^{+}, \mathrm{TCR} \beta^{+}, \mathrm{NK} 1.1^{-}, \mathrm{CD} 4^{+}\right)$, $\mathrm{CD}^{+}{ }^{+}$cells $\left(\mathrm{CD} 45^{+}, \mathrm{TCR}^{+}, \mathrm{NK}^{+} 1^{-}, \mathrm{CD} 8^{+}\right)$, NKT cells $\left(\mathrm{CD} 45^{+}, \mathrm{TCR} \beta^{+}\right.$, $\left.\mathrm{NK} 1.1^{+}\right)$and Tregs $\left(\mathrm{CD} 45^{+}, \mathrm{TCR} \beta^{+}, \mathrm{NK} 1.1^{-}, \mathrm{CD} 4^{+}, \mathrm{CD} 25^{+}, \mathrm{Foxp} 3^{+}\right)$were identified with the appropriate gating.

Cell sorting. Tumours from WT and $A b c g 1^{-1-}$ mice at day 20 were enriched for $\mathrm{CD} 11 \mathrm{~b}^{+}$cells by positive selection with mouse $\mathrm{CD} 11 \mathrm{~b}^{+}$positive selection kit (Stem Cell Technologies, Vancouver, Canada) according to the manufacturer's instructions, before cell sorting. Surface antigens on enriched $\mathrm{CD}_{11 \mathrm{~b}}{ }^{+}$cells were then stained as described above, followed by macrophage (Ly6G ${ }^{-}, \mathrm{NK}_{1.1}{ }^{-}$, $\left.\mathrm{CD}_{11} \mathrm{~b}^{+}, \mathrm{F} 4 / 80^{\mathrm{high}}\right)$ sorting with a FACSAria cytometer (BD Biosciences). Peritoneal lavage from $A b c g 1^{\mathrm{fl} / \mathrm{fl}}$-LysM-Cre ${ }^{+}$and $\mathrm{Abcg} 1^{\mathrm{f} / \mathrm{fl}}$-LysM-Cre ${ }^{-}$mice 5 days post thioglycollate injection was sorted for macrophages ( $\left.\mathrm{F} 4 / 80^{\text {high }}\right)$ and splenocytes from $A b c g 1^{\mathrm{fl} / \mathrm{fl}}$-Lck-Cre ${ }^{+}$and $A b c g 1^{\mathrm{fl} / \mathrm{fl}}$-Lck-Cre ${ }^{-}$mice were sorted for $\mathrm{T}$ cells $\left(\mathrm{CD}^{+}{ }^{+}\right)$using FACSAria cytometer.

Tumour angiogenesis. Tumours were minced and digested with Collagenase IV $\left(400 \mathrm{U} \mathrm{ml}^{-1}\right)$ in the presence of DNase I $\left(20 \mu \mathrm{g} \mathrm{ml}^{-1}\right)$ in RPMI medium at $37^{\circ} \mathrm{C}$ for $30 \mathrm{~min}$. Cell suspension was filtered through a $40-\mu \mathrm{m}$ strainer and resuspended in warm R5 medium and incubated at $37^{\circ} \mathrm{C}$ for $30 \mathrm{~min}$. The cells were stained with fluorophore-conjugated antibodies against CD45, CD31, CD34 and analysed by flow cytometry.

Generation and M1/M2 polarization of BMDMs. BMDMs were prepared as described previously ${ }^{62,63}$. In brief, bone marrow cells were cultured in standard tissue culture plates in the presence of $10 \mathrm{ng} \mathrm{ml}^{-1} \mathrm{M}$-CSF overnight. Nonadherent cells from this initial culture were then transferred to low-attachment sixwell plates (Corning Life Sciences, Tewksbury MA) in $4 \mathrm{ml} \mathrm{R} 5$ medium containing $30 \% \mathrm{~L} 929$ conditioned medium and $10 \mathrm{ng} \mathrm{ml}^{-1} \mathrm{M}$-CSF per well for 7 days, adding more medium on days 3 and 6 . After that, the cells were purified by centrifugation over Ficoll-Paque plus. Cells were verified to be $98 \% \mathrm{CD} 1 \mathrm{~b}^{+}, \mathrm{F} 4 / 80^{+}$, MHC $\mathrm{II}^{\text {low }}, \mathrm{CD} 80^{\text {low }}, \mathrm{CD} 86^{\text {low }}$ by flow cytometry.

WT and $A b c g 1^{-1-}$ BMDMs were allowed to rest at $37^{\circ} \mathrm{C}$ over night before stimulation. For M1 polarization, macrophages were either stimulated with IFN $\gamma$ $\left(20 \mathrm{ng} \mathrm{ml}^{-1}\right)$ for $12 \mathrm{~h}$ followed by LPS $\left(100 \mathrm{ng} \mathrm{ml}^{-1}\right)$ stimulation for $4 \mathrm{~h}$ (for MHC II and CD86 analysis) or stimulated with IFN $\gamma\left(20 \mathrm{ng} \mathrm{ml}^{-1}\right)+\mathrm{LPS}\left(100 \mathrm{ng} \mathrm{ml}^{-1}\right)$ overnight (for TNF $\alpha$ and NO analysis). For M2 polarization, macrophages were stimulated with IL-4 $\left(20 \mathrm{ng} \mathrm{ml}^{-1}\right)$ for $16 \mathrm{~h}$.
Stimulation of macrophages with cholesterol and -derivatives. WT BMDMs were allowed to rest at $37^{\circ} \mathrm{C}$ over night before stimulation. The next day, macrophages were preincubated with water-soluble cholesterol $\left(20 \mu \mathrm{g} \mathrm{ml}^{-1}\right)$, $7 \alpha$-OHC $(1 \mu \mathrm{M}), 25-\mathrm{OHC}(1 \mu \mathrm{M}), 27-\mathrm{OHC}(1 \mu \mathrm{M})$, desmosterol $(5 \mu \mathrm{M})$ or $7-\mathrm{KC}$ $(5 \mu \mathrm{M})$ for $2 \mathrm{~h}$. Next, macrophages were either left unstimulated or stimulated with IFN $\gamma\left(20 \mathrm{ng} \mathrm{ml}^{-1}\right)$ for $12 \mathrm{~h}$ followed by LPS $\left(100 \mathrm{ng} \mathrm{ml}^{-1}\right)$ stimulation for $4 \mathrm{~h}$ (for MHC II analysis) or stimulated with IFN $\gamma\left(20 \mathrm{ng} \mathrm{ml}^{-1}\right)+\mathrm{LPS}\left(100 \mathrm{ng} \mathrm{ml}^{-1}\right)$ overnight (for $\mathrm{TNF} \alpha$ analysis).

Cytokine and NO measurements. The supernatants were collected and TNF $\alpha$ was measured by ELISA (eBioscience) and NO (as nitrite) was measured by the Griess Reagent System (Promega, Madison, WI) according to the manufacturers' instructions.

In vitro tumour cytotoxicity assay. WT and $A b c g 1^{-1-}$ BMDMs were plated in round well 96-well plates as $4 \times 10^{5}$ cells per well in $200 \mu \mathrm{l} \mathrm{R} 5$ and stimulated with IFN $\gamma\left(20 \mathrm{ng} \mathrm{ml}^{-1}\right)$ and LPS $\left(100 \mathrm{ng} \mathrm{ml}^{-1}\right)$ for $24 \mathrm{~h}$. The cells were washed with R5 twice and co-cultured with $10^{4}$ MB49 tumour cells (40:1 ratio of effector (macrophages): target cells (tumour cells) ). Twenty four hours later, the cells were washed with PBS and treated with Accutase cell detachment solution (BD Biosciences). Tumour cell viability was determined with 7 -aminoactinomycin D (7-AAD) staining by flow cytometry. Tumour cytotoxicity was calculated as $\%$ of 7-AAD ${ }^{+}$tumour cells $\left(\mathrm{CD} 45^{-}, \mathrm{F} 4 / 80^{-}\right)$co-cultured with macrophages $\left(\mathrm{CD} 45^{+}\right.$, $\left.\mathrm{F} 4 / 80^{+}\right)-\% 7-\mathrm{AAD}^{+}$of tumour cells alone.

Quantitative real-time PCR. Total cellular RNA of macrophages was collected with an RNeasy Plus Micro Kit according to the manufacturer's protocol (Qiagen, Valencia, CA). RNA purity and quantity was measured with a nanodrop spectrophotometer (Thermo Scientific). Approximately $500 \mathrm{ng}$ RNA was used for synthesis of cDNA with an Iscript cDNA Synthesis Kit (Bio-Rad, Hercules, CA). Total cDNA was diluted $1: 20$ in $\mathrm{H}_{2} \mathrm{O}$ and a volume of $9 \mu \mathrm{l}$ was used for each real-time condition with a MyIQ Single-Color Real-Time PCR Detection System (Bio-Rad) and TaqMan Gene Expression Mastermix and Arg1 (\# Mm00475988_m1), Ccl22 (\# Mm00436439_m1), Mrcl (\# Mm00485148_m1), Tnfa (\# Mm00443258_m1), Rtnla (\# Mm00445109_m1), Nos2 (\# Mm00440502_ m1), Abcg1 (\# Mm01348250_m1) and Abca1 (\# Mm01350760_m1) TaqMan primers (Applied Biosystems). Data were analysed and presented on the basis of the relative expression method ${ }^{64}$. The formula for this calculation is as follows: relative expression $=2^{-(\mathrm{S} \Delta \mathrm{Ct}-\mathrm{C} \dot{\mathrm{C}} \mathrm{C} t)}$ where $\Delta C_{t}$ is the difference in the threshold cycle between the gene of interest and the housekeeping gene (18S), $\mathrm{S}$ is the $A b c 1^{-1-}$ mouse and $\mathrm{C}$ is the WT mouse.

Statistical analyses. Data for all experiments were analysed with Prism software (GraphPad). Two-way analysis of variance test, long-rank test, unpaired Student's $t$-test and Wilcoxon-matched-pairs signed rank test were used for comparison of experimental groups when appropriate. The data shown are the means \pm s.e.m. $P$ values of less than 0.05 were considered statistically significant.

\section{References}

1. Grivennikov, S. I., Greten, F. R. \& Karin, M. Immunity, inflammation, and cancer. Cell 140, 883-899.

2. Whiteside, T. L. The tumor microenvironment and its role in promoting tumor growth. Oncogene 27, 5904-5912 (2008).

3. Mantovani, A., Sica, A. \& Locati, M. Macrophage polarization comes of age. Immunity 23, 344-346 (2005).

4. Martinez, F. O., Helming, L. \& Gordon, S. Alternative activation of macrophages: an immunologic functional perspective. Annu. Rev. Immunol. 27, 451-483 (2009).

5. Solinas, G., Germano, G., Mantovani, A. \& Allavena, P. Tumor-associated macrophages (TAM) as major players of the cancer-related inflammation. J. Leukoc. Biol. 86, 1065-1073 (2009).

6. Coussens, L. M. \& Werb, Z. Inflammation and cancer. Nature 420, 860-867 (2002).

7. Lewis, C. E. \& Pollard, J. W. Distinct role of macrophages in different tumor microenvironments. Cancer Res. 66, 605-612 (2006).

8. Mantovani, A., Sozzani, S., Locati, M., Allavena, P. \& Sica, A. Macrophage polarization: tumor-associated macrophages as a paradigm for polarized M2 mononuclear phagocytes. Trends Immunol. 23, 549-555 (2002).

9. Pollard, J. W. Tumour-educated macrophages promote tumour progression and metastasis. Nat. Rev. Cancer 4, 71-78 (2004).

10. Nishikawa, H. \& Sakaguchi, S. Regulatory T cells in tumor immunity. Int. J. Cancer 127, 759-767.

11. Sica, A. et al. Macrophage polarization in tumour progression. Semin. Cancer Biol. 18, 349-355 (2008).

12. Hiraoka, K. et al. Inhibition of bone and muscle metastases of lung cancer cells by a decrease in the number of monocytes/macrophages. Cancer Sci. 99, 1595-1602 (2008). 
13. Lin, E. Y. et al. Macrophages regulate the angiogenic switch in a mouse model of breast cancer. Cancer Res. 66, 11238-11246 (2006).

14. Lin, E. Y., Nguyen, A. V., Russell, R. G. \& Pollard, J. W. Colony-stimulating factor 1 promotes progression of mammary tumors to malignancy. J. Exp. Med. 193, 727-740 (2001).

15. Miselis, N. R., Wu, Z. J., Van Rooijen, N. \& Kane, A. B. Targeting tumorassociated macrophages in an orthotopic murine model of diffuse malignant mesothelioma. Mol. Cancer Ther. 7, 788-799 (2008).

16. Zeisberger, S. M. et al. Clodronate-liposome-mediated depletion of tumourassociated macrophages: a new and highly effective antiangiogenic therapy approach. Br. J. Cancer 95, 272-281 (2006).

17. Colombo, M. P. \& Mantovani, A. Targeting myelomonocytic cells to revert inflammation-dependent cancer promotion. Cancer Res. 65, 9113-9116 (2005).

18. Guiducci, C., Vicari, A. P., Sangaletti, S., Trinchieri, G. \& Colombo, M. P. Redirecting in vivo elicited tumor infiltrating macrophages and dendritic cells towards tumor rejection. Cancer Res. 65, 3437-3446 (2005).

19. Ostrand-Rosenberg, S., Grusby, M. J. \& Clements, V. K. Cutting edge: STAT6deficient mice have enhanced tumor immunity to primary and metastatic mammary carcinoma. J. Immunol. 165, 6015-6019 (2000).

20. Tarr, P. T., Tarling, E. J., Bojanic, D. D., Edwards, P. A. \& Baldan, A. Emerging new paradigms for ABCG transporters. Biochim. Biophys. Acta 1791, 584-593 (2009).

21. Ikonen, E. Cellular cholesterol trafficking and compartmentalization. Nat. Rev. Mol. Cell Biol. 9, 125-138 (2008).

22. Kennedy, M. A. et al. ABCG1 has a critical role in mediating cholesterol efflux to HDL and preventing cellular lipid accumulation. Cell Metab. 1, 121-131 (2005).

23. Wang, N., Lan, D., Chen, W., Matsuura, F. \& Tall, A. R. ATP-binding cassette transporters G1 and G4 mediate cellular cholesterol efflux to high-density lipoproteins. Proc. Natl Acad. Sci. USA 101, 9774-9779 (2004).

24. Sturek, J. M. et al. An intracellular role for ABCG1-mediated cholesterol transport in the regulated secretory pathway of mouse pancreatic beta cells. J. Clin. Invest. 120, 2575-2589 (2010).

25. Tarling, E. J. \& Edwards, P. A. ATP binding cassette transporter G1 (ABCG1) is an intracellular sterol transporter. Proc. Natl Acad. Sci. USA 108, 19719-19724 (2011).

26. Baldan, A. et al. Impaired development of atherosclerosis in hyperlipidemic Ldlr - / - and ApoE - / - mice transplanted with Abcg1 - / - bone marrow. Arterioscler. Thromb. Vasc. Biol. 26, 2301-2307 (2006).

27. Tarling, E. J. et al. Impaired development of atherosclerosis in Abcg1 - / Apoe - / - mice: identification of specific oxysterols that both accumulate in Abcg1 - / - Apoe - / - tissues and induce apoptosis. Arterioscler. Thromb. Vasc. Biol. 30, 1174-1180.

28. Baldan, A., Gomes, A. V., Ping, P. \& Edwards, P. A. Loss of ABCG1 results in chronic pulmonary inflammation. J. Immunol. 180, 3560-3568 (2008)

29. Wojcik, A. J., Skaflen, M. D., Srinivasan, S. \& Hedrick, C. C. A critical role for ABCG1 in macrophage inflammation and lung homeostasis. J. Immunol. 180, 4273-4282 (2008).

30. Yvan-Charvet, L. et al. Increased inflammatory gene expression in ABC transporter-deficient macrophages: free cholesterol accumulation, increased signaling via toll-like receptors, and neutrophil infiltration of atherosclerotic lesions. Circulation 118, 1837-1847 (2008).

31. Yvan-Charvet, L. et al. Combined deficiency of ABCA1 and ABCG1 promotes foam cell accumulation and accelerates atherosclerosis in mice. J. Clin. Invest. 117, 3900-3908 (2007).

32. Armstrong, A. J., Gebre, A. K., Parks, J. S. \& Hedrick, C. C. ATP-binding cassette transporter G1 negatively regulates thymocyte and peripheral lymphocyte proliferation. J. Immunol. 184, 173-183.

33. Bensinger, S. J. et al. LXR signaling couples sterol metabolism to proliferation in the acquired immune response. Cell 134, 97-111 (2008).

34. Sag, D. et al. ATP-binding cassette transporter G1 intrinsically regulates invariant NKT cell development. J. Immunol. 189, 5129-5138 (2012).

35. Baldan, A. et al. Deletion of the transmembrane transporter ABCG1 results in progressive pulmonary lipidosis. J. Biol. Chem. 281, 29401-29410 (2006).

36. Ranalletta, M. et al. Decreased atherosclerosis in low-density lipoprotein receptor knockout mice transplanted with Abcg1 - / - bone marrow. Arterioscler. Thromb. Vasc. Biol. 26, 2308-2315 (2006)

37. Plump, A. S. et al. Severe hypercholesterolemia and atherosclerosis in apolipoprotein E-deficient mice created by homologous recombination in ES cells. Cell 71, 343-353 (1992).

38. Zhang, S. H., Reddick, R. L., Piedrahita, J. A. \& Maeda, N. Spontaneous hypercholesterolemia and arterial lesions in mice lacking apolipoprotein E. Science 258, 468-471 (1992)

39. Ishibashi, S. et al. Hypercholesterolemia in low density lipoprotein receptor knockout mice and its reversal by adenovirus-mediated gene delivery. J. Clin Invest. 92, 883-893 (1993)

40. Ishibashi, S., Goldstein, J. L., Brown, M. S., Herz, J. \& Burns, D. K. Massive xanthomatosis and atherosclerosis in cholesterol-fed low density lipoprotein receptor-negative mice. J. Clin. Invest. 93, 1885-1893 (1994).
41. Ishibashi, S., Herz, J., Maeda, N., Goldstein, J. L. \& Brown, M. S. The tworeceptor model of lipoprotein clearance: tests of the hypothesis in 'knockout' mice lacking the low density lipoprotein receptor, apolipoprotein E, or both proteins. Proc. Natl Acad. Sci. USA 91, 4431-4435 (1994).

42. Nathanson, S. D., Haas, G. P., Mead, M. J. \& Lee, M. Spontaneous regional lymph node metastases of three variants of the B16 melanoma: relationship to primary tumor size and pulmonary metastases. J. Surg. Oncol. 33, 41-45 (1986).

43. Stackpole, C. W. Intrapulmonary spread of established B16 melanoma lung metastases and lung colonies. Invasion Metastasis 10, 267-280 (1990).

44. Swann, J., Crowe, N. Y., Hayakawa, Y., Godfrey, D. I. \& Smyth, M. J. Regulation of antitumour immunity by CD1d-restricted NKT cells. Immunol. Cell Biol. 82, 323-331 (2004).

45. Hennet, T., Hagen, F. K., Tabak, L. A. \& Marth, J. D. T-cell-specific deletion of a polypeptide $\mathrm{N}$-acetylgalactosaminyl-transferase gene by site-directed recombination. Proc. Natl Acad. Sci. USA 92, 12070-12074 (1995).

46. Clausen, B. E., Burkhardt, C., Reith, W., Renkawitz, R. \& Forster, I. Conditional gene targeting in macrophages and granulocytes using LysMcre mice. Transgenic Res. 8, 265-277 (1999).

47. Gelissen, I. C. et al. ABCA1 and ABCG1 synergize to mediate cholesterol export to apoA-I. Arterioscler. Thromb. Vasc. Biol. 26, 534-540 (2006).

48. Vaughan, A. M. \& Oram, J. F. ABCA1 and ABCG1 or ABCG4 act sequentially to remove cellular cholesterol and generate cholesterol-rich HDL. J. Lipid Res. 47, 2433-2443 (2006).

49. Vedhachalam, C. et al. Mechanism of ATP-binding cassette transporter A1-mediated cellular lipid efflux to apolipoprotein A-I and formation of high density lipoprotein particles. J. Biol. Chem. 282, 25123-25130 (2007).

50. Movahedi, K. et al. Different tumor microenvironments contain functionally distinct subsets of macrophages derived from Ly6C(high) monocytes. Cancer Res. 70, 5728-5739 (2010)

51. Terasaka, N., Wang, N., Yvan-Charvet, L. \& Tall, A. R. High-density lipoprotein protects macrophages from oxidized low-density lipoproteininduced apoptosis by promoting efflux of 7-ketocholesterol via ABCG1. Proc. Natl Acad. Sci. USA 104, 15093-15098 (2007).

52. Karin, M. \& Delhase, M. The I kappa B kinase (IKK) and NF-kappa B: key elements of proinflammatory signalling. Semin. Immunol. 12, 85-98 (2000)

53. Hu, J., Nakano, H., Sakurai, H. \& Colburn, N. H. Insufficient p65 phosphorylation at S536 specifically contributes to the lack of NF-kappaB activation and transformation in resistant JB6 cells. Carcinogenesis 25, 1991-2003 (2004).

54. Escorcio-Correia, M. \& Hagemann, T. Measurement of tumor cytolysis by macrophages. Curr. Protoc. Immunol. Chapter 14, Unit 1418 11-11 (2011)

55 . Li, Y. et al. Free cholesterol-loaded macrophages are an abundant source of tumor necrosis factor-alpha and interleukin-6: model of NF-kappaB- and map kinase-dependent inflammation in advanced atherosclerosis. J. Biol. Chem. 280 , 21763-21772 (2005).

56. Brunham, L. R. et al. Beta-cell ABCA1 influences insulin secretion, glucose homeostasis and response to thiazolidinedione treatment. Nat. Med. 13, 340-347 (2007)

57. Rye, K. A., Bursill, C. A., Lambert, G., Tabet, F. \& Barter, P. J. The metabolism and anti-atherogenic properties of HDL. J. Lipid Res. 50 Suppl, S195-S200 (2009).

58. Jafri, H., Alsheikh-Ali, A. A. \& Karas, R. H. Baseline and on-treatment highdensity lipoprotein cholesterol and the risk of cancer in randomized controlled trials of lipid-altering therapy. J. Am. Coll. Cardiol. 55, 2846-2854 (2010).

59. Zamanian-Daryoush, M. et al. The cardioprotective protein apolipoprotein A1 promotes potent anti-tumorigenic effects. J. Biol. Chem. 288, 21237-21252 (2013).

60. Castellani, L. W. et al. Overexpression of apolipoprotein AII in transgenic mice converts high density lipoproteins to proinflammatory particles. J. Clin. Invest. 100, 464-474 (1997).

61. Warden, C. H., Hedrick, C. C., Qiao, J. H., Castellani, L. W. \& Lusis, A. J. Atherosclerosis in transgenic mice overexpressing apolipoprotein A-II. Science 261, 469-472 (1993).

62. Cekic, C. et al. MyD88-dependent SHIP1 regulates proinflammatory signaling pathways in dendritic cells after monophosphoryl lipid A stimulation of TLR4 J. Immunol. 186, 3858-3865 (2011).

63. Sag, D., Carling, D., Stout, R. D. \& Suttles, J. Adenosine $5^{\prime}$-monophosphateactivated protein kinase promotes macrophage polarization to an antiinflammatory functional phenotype. J. Immunol. 181, 8633-8641 (2008).

64. Livak, K. J. \& Schmittgen, T. D. Analysis of relative gene expression data using real-time quantitative PCR and the 2(-Delta Delta C(T)) Method. Methods 25, 402-408 (2001).

\section{Acknowledgements}

We thank Amy Blatchley, Debbi Yoakum, Fernando Vazquez, Dr Iftach Shaked, the Department of Laboratory Animal Care and the Flow Cytometry Facility at the La Jolla Institute for Allergy and Immunology (LJI) for excellent technical assistance. We thank 
Dr Gerhard Wingender and Dr Klaus Ley at LJI for valuable scientific contributions. We also thank Jennifer Pattison and Dr Joseph Witztum at University of California San Diego for assistance with plasma lipoprotein analysis. This work was supported by NIH R01 HL097368 (to C.C.H.) and NIH P01 HL55798 (to C.C.H.).

\section{Author contributions}

D.S and C.C. designed and performed the experiments and analysed the data; R.W. provided technical assistance; J.L. provided intellectual input; C.C.H. and D.S. supervised the overall study and advised on study design and data interpretation; D.S. and C.C.H. wrote the manuscript.

\section{Additional information}

Supplementary Information accompanies this paper at http://www.nature.com/ naturecommunications

Competing financial interests: The authors declare no competing financial interests.

Reprints and permission information is available online at http://npg.nature.com/ reprintsandpermissions/

How to cite this article: Sag, D. et al. The cholesterol transporter ABCG1 links cholesterol homeostasis and tumour immunity. Nat. Commun. 6:6354 doi: $10.1038 /$ ncomms7354 (2015). 